Transportation Research Forum

Did Passenger Fare Savings Occur After Airline Deregulation?

Author(s): David B. Richards

Source: Journal of the Transportation Research Forum, Vol. 46, No. 1 (Spring 2007), pp. 73-93

Published by: Transportation Research Forum

Stable URL: http://www.trforum.org/journal

The Transportation Research Forum, founded in 1958, is an independent, nonprofit organization of transportation professionals who conduct, use, and benefit from research. Its purpose is to provide an impartial meeting ground for carriers, shippers, government officials, consultants, university researchers, suppliers, and others seeking exchange of information and ideas related to both passenger and freight transportation. More information on the Transportation Research Forum can be found on the Web at www.trforum.org. 


\title{
Did Passenger Fare Savings Occur After Airline Deregulation?
}

\author{
by David B. Richards
}

This paper questions the generally held belief that there are significant passenger fare savings and increased passenger traffic growth due to airline deregulation. Unlike previous studies, passengers and passenger fares are broken into discrete distance intervals and compared to passenger and fare distributions prior to deregulation. Except for the period immediately before the terrorist attack in 2001 and continuing through 2005, there are limited, if any, demonstrable domestic system passenger fare savings. Also in contrast to other papers showing significant passenger fare benefits, virtually all data for this paper is accessible via the Internet.

\section{INTRODUCTION}

It is surprising that anyone expected fares to fall with the advent of airline deregulation. This conclusion directly differs from the economic maxim, "Charge what the market will bear." In addition, since the start of the Domestic Passenger Fare Investigation (DPFI) in 1970, most of the Civil Aeronautics Board's (CAB) major activities in the pricing area had dealt with the development of economic criteria that would basically suppress fare increases unless those criteria were met. That suppression was removed with the Airline Deregulation Act of 1978 (ADA).

Deregulation was presented as an opportunity for consumers to benefit from lower fares and improved service as federal regulatory constraints were removed. Federally regulated fares were unfavorably compared to lower non-federally regulated fares in California and Texas, with little notice paid to the more severe price regulation in California, nor to the general monopoly intra-state services granted by the public utility commissions of both states. There was little effort by the proderegulation $\mathrm{CAB}$ to provide guidance. Because lower fares and higher traffic were predicted to occur because of deregulation, studies designed to measure such results began to proliferate shortly after airline deregulation occurred.

These studies invariably have something in common -- unrealistic assumptions about what the regulated fare level would have been had regulation continued and relatively weak analysis of traffic growth and yield. Because the constructed regulatory fare was invariably too high, a comparison to deregulated fare levels has always shown large savings.

Domestic industry data for traffic and price are shown below; overall traffic is measured by revenue passenger-miles, and price is measured by revenue per revenue passenger-mile, or yield (see Figures 1 and 2). Changes in cost and productivity are briefly examined to determine if there are significant cost savings or productivity increases that would have allowed lower prices to the consumer after deregulation.

Following the cost and productivity information is a discussion of rate-setting policies under the Civil Aeronautic Board's (CAB) Domestic Passenger Fare Investigation (DPFI)(1975) and updates to the DPFI fare level after deregulation under the Standard Industry Fare Level (SIFL), a fare zone of reasonableness standard required by the Airline Deregulation Act of 1978 (ADA)(U. S. Congress 1978). Market concentration and its relationship to the SIFL are briefly examined. Estimates of passenger fare premiums or savings after deregulation, derived from the CAB and the U.S. Department of Transportation's 10\% passenger ticket survey, incorporate the SIFL. 


\section{PASSENGER TRAFFIC BETWEEN 1951 AND 2005}

Below is a graph of domestic industry revenue passenger-miles in logarithmic scale. A straight line on a logarithmic graph indicates a constant rate of change. ${ }^{1}$ Two visually fitted lines have been added for emphasis, 1951-1979 and 1979-2005. One could fit alternate lines, but it would be difficult to show greater growth in traffic for periods after deregulation than before. The rate of traffic growth has clearly not increased, despite the relative increase in passenger circuity caused by the general adoption of the hub-spoke system.

\section{Figure 1: Domestic Industry Revenue-Passenger Miles, 1951-2005 (millions)}

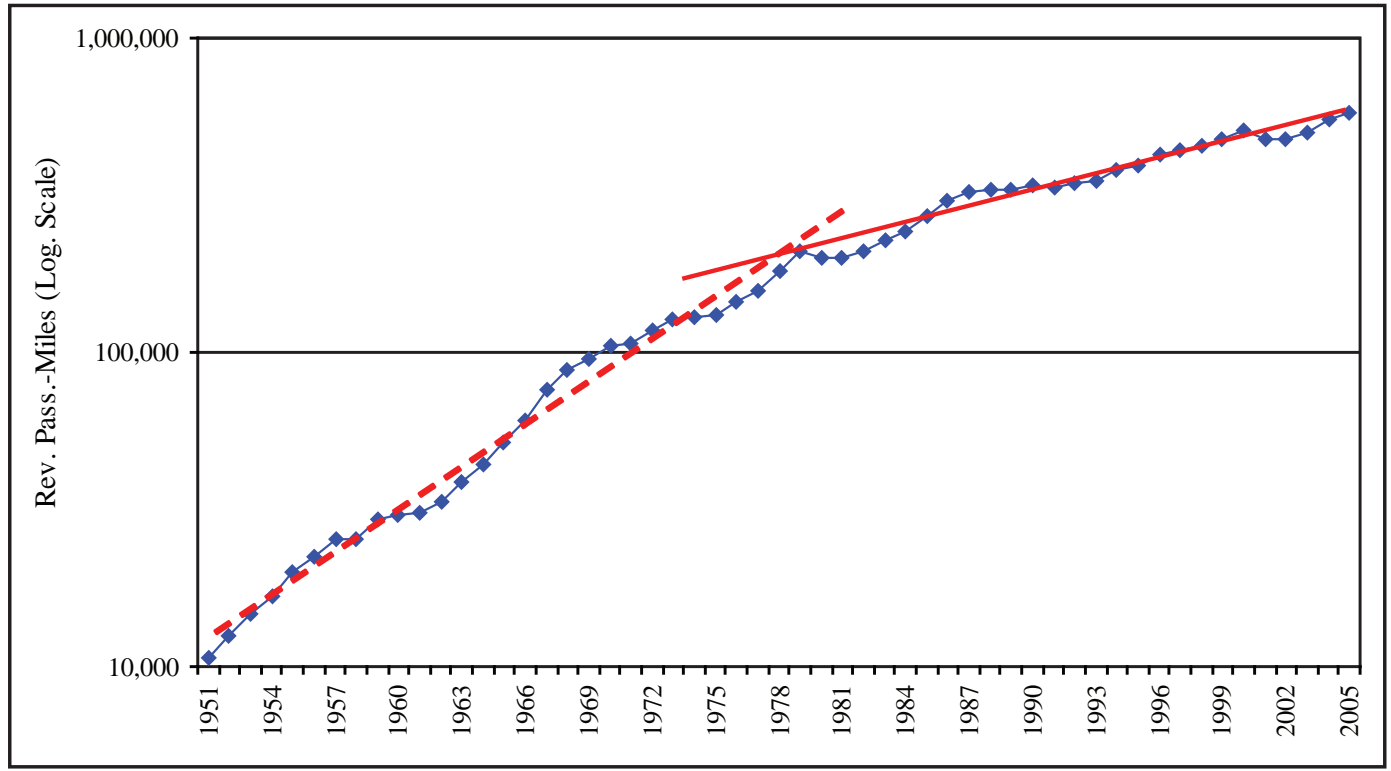

Source: U.S. Department of Transportation, Bureau of Transportation Statistics and predecessors.

\section{AVERAGE YIELD PER PASSENGER-MILE BETWEEN 1950 AND 2005}

Average domestic real yield per passenger-mile shows a relatively continuous decline since the middle-to-late 1960s, with a slight flattening from about 1994 through 2000. The decline in average yield has often been presented as a benefit of airline deregulation, with little analysis of the yield decline before airline deregulation, or whether that decline would have continued after deregulation.

While there does not appear to be any marked change in trend with airline deregulation in 1979, this does not mean there were no changes in the fare structure. Morrison and Winston (1995), Borenstein and Rose (forthcoming), and the U.S. Government Accountability Office (2006), among others, have documented a significant increase in market fare dispersion after deregulation. This should not be surprising. The cost disallowances for discount fares under regulation (discussed under the DPFI, below) were removed, allowing lower discount fares, and the fare ceiling proscriptions were cancelled, allowing significant increases in premium fares, including regular coach fares. Average fares, however, tend to net out both fare reductions and increases.

\section{LEVEL OF INPUT COSTS AND PRODUCTIVITY AFTER AIRLINE DEREGULATION}

One of the major determinants of yield is the level of the input costs that must be recovered to operate profitably. While there are a number of major cost elements that could be considered for 
Figure 2: Domestic Industry Nominal and Real Yield per Passenger-Mile, 1950-2005

$($ CPI-U, 1982-84 = 100)

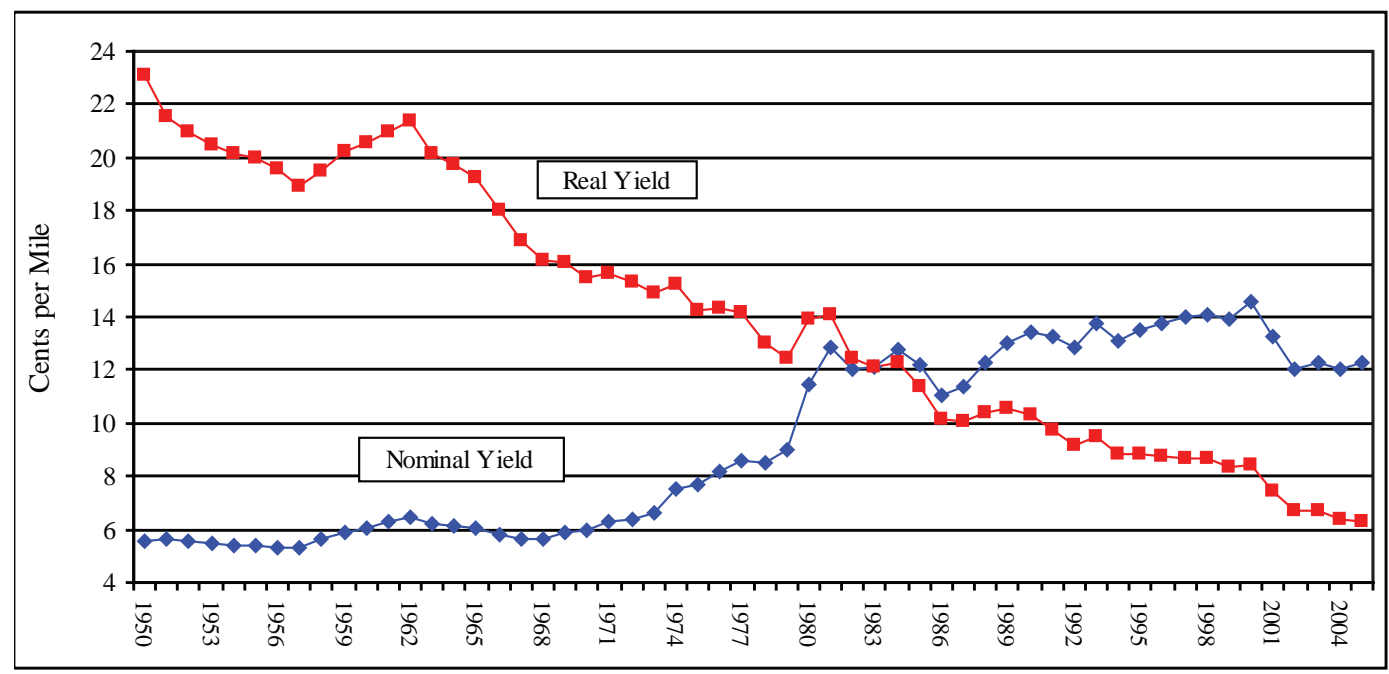

Source: Air Transport Association (www.airlines.org/economics/finance/PaPricesYield.htm)

analysis, historically cost per available seat-mile was a major regulatory standard, often measured indirectly through load factor standards (also discussed under the DPFI below). Cost per seat-mile was separated between fuel and non-fuel costs, both because fuel was a major exogenous cost component, and because carriers were presumed to exercise more control over other cost elements. This was continued after deregulation with the Congressional requirement that a cost index, the Standard Industry Fare Level (SIFL, also discussed below), be regularly computed by the regulatory authorities. The SIFL index continued the separation of fuel and non-fuel cost components.

Figure 3: Fuel, Non-fuel, and Total Cost per Seat-Mile (SIFL Methodology), July 1979 - January 2006

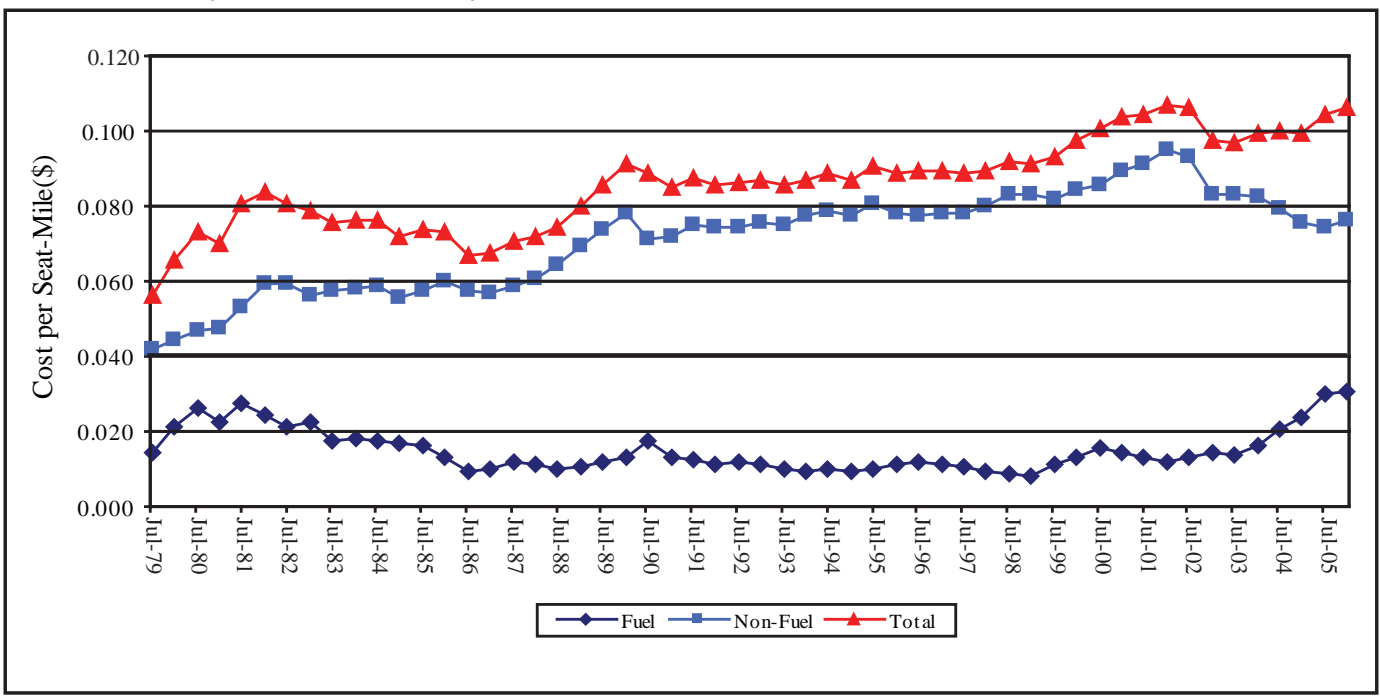

Source: U.S. Department of Transportation, Office of Domestic Aviation (http://www.ostpxweb.dot.gov/ aviation/domesticaffairs.htm\#sifl) 
Passenger Fare Savings

As can be seen above, fuel costs increased immediately after deregulation, but declined to approximate pre-deregulation levels by 1983, and had limited variation from 1986 through 2003. There were brief spikes due to oil supply shortfalls. The major component of rising total cost was the increase in non-fuel cost. Figure 4 shows the unit costs per available seat-mile for major cost categories for the major and national domestic passenger carriers between 1971 and 2005 . (Transport-related expenses are not shown because of the inclusion of commuter affiliate expenses in industry data.)

Figure 4: Unit Cost per Available Seat-Mile for the Domestic Major and National Air Carriers, 1971-2005

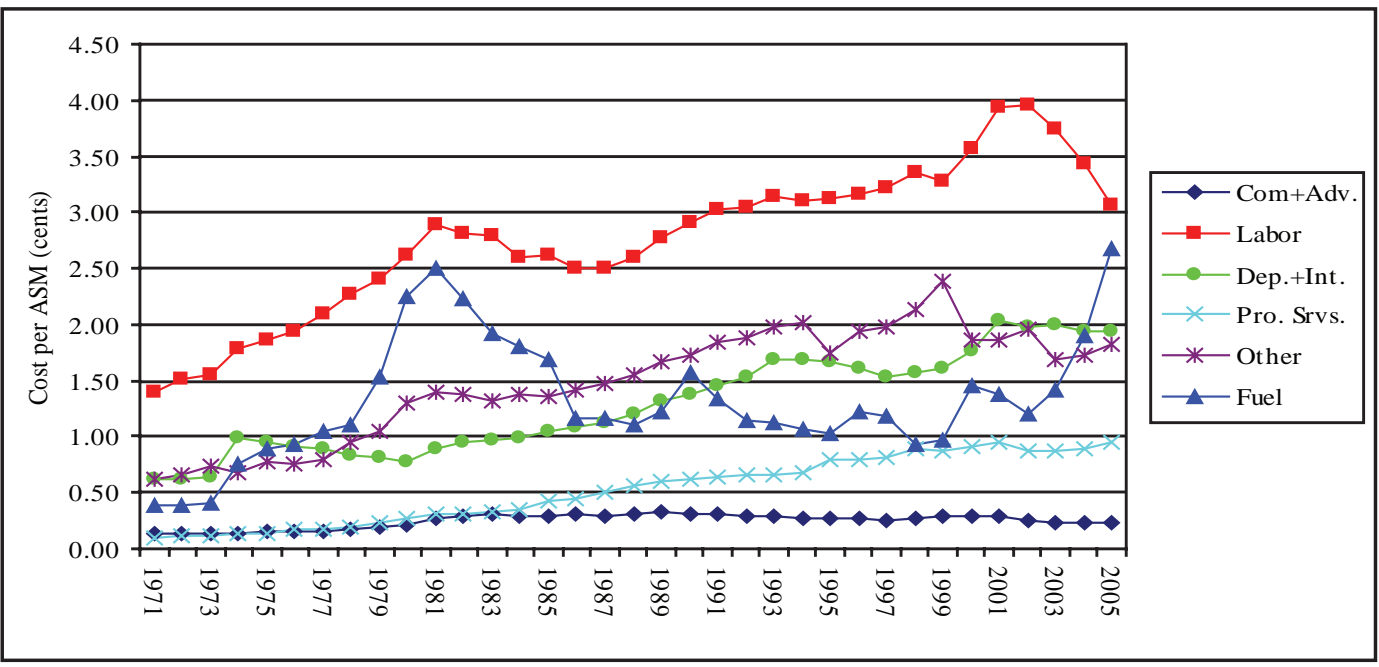

Source: Air Transport Association (http://airlines.org/economics/finance/CostIndex.htm)

Except for the period 1981-1986 (during and immediately after the largest increase in average aircraft size during the period 1971-2005), and the industry restructuring that occurred after 2002, unit labor cost generally stayed the same approximate percentage of total cost (38.0\% in 1979, 33.8.1\% in 2000). There is disagreement as to whether this represents the continued ability of labor unions to extract a wage premium. In any case, the payment of increased wages by the air carriers as opposed to incurring a strike was likely due to two factors. First, as market competition increased with the removal of carrier route constraints after deregulation, a carrier shutdown for a strike meant the immediate loss of market share that would become more difficult to regain the longer the strike. Second, the carrier Mutual Aid Pact, under which a carrier would pay a portion of its gains due to another carrier taking a strike, was removed by the Deregulation Act. ${ }^{2}$ The result was an increasing wage level generally unrelated to general inflation or increased productivity.

Determining the cause of changes in productivity after deregulation is problematic. Historically, productivity has been measured as available ton-miles per employee, because carriers tended to provide both freight and passenger scheduled and charter services. Few passenger carriers now provide separate freight services, and there are limited charter passenger services. Productivity is now generally measured in available seat-miles (ASM) per employee. Some have measured efficiency gains (losses) through changes in passenger load factor. However, load factor is partly determined by the size of the aircraft. While significant increases in load factor have occurred after deregulation, most of that increase was the result of a marked reduction in aircraft seats per aircraftmile. The 13.8 percentage point gain in load factor between 1983 (59.6\%) and 2004 (74.4\%), is only about one percentage point more than the $12.9 \%$ reduction in average aircraft size over the same period (1983, 163.1 seats; 2004, 142.1 seats). Here the use of available seats per mile per 
full-time employee equivalents will be used as a surrogate for productivity, as provided by the Air Transport Association and similar to that used by the GAO.

Figure 5 compares ASM per employee and average seats per aircraft-mile. As can be seen, the largest increases in productivity, except for the period following the industry restructuring in 2001-2004, occurred during and immediately after one of the largest increase in average aircraft size (1981-1983) since the introduction of jet aircraft. The productivity increase can be attributed, in some part, to the lingering effects of the PATCO strike in 1981 (the controller's strike reduced the number of available takeoff/landing positions at major airports, causing carriers to increase the use of larger aircraft where operations were constrained.) Since average aircraft size has been declining since 1983, it is likely that productivity's return to trend by 1990 reflected the gradual loss of aircraft size efficiencies. In any case, there does not appear to be any structural increase in productivity until the carrier reorganizations in 2002.

Figure 5: Available Seat-Miles per Employee and Average Seats per Aircraft-Mile, 1972-2004

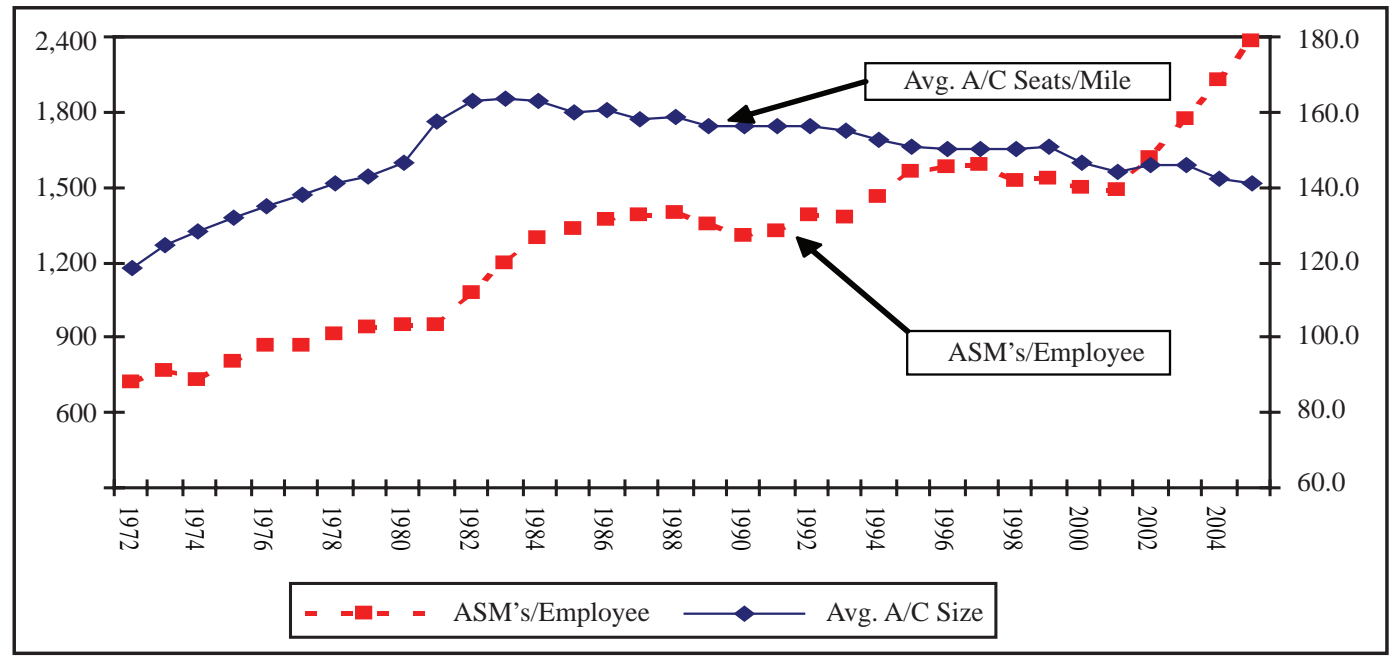

Source: Air Transport Association (http://airlines.org/economics/traffic/Annual+US+Traffic.htm) and U.S. Department of Transportation, Bureau of Transportation Statistics, Traffic Statistics of Certificated Route Air Carriers, selected issues.

This short examination of elements contributing to cost or productivity and which would affect average yield does not show any specific items which would support a claim that the period after deregulation has resulted in a lower average yield through cost reduction or productivity increases. Average yield, however, is an average; the effect of changes in passenger fares and yield by mileage interval that contribute to that average is examined in the following sections.

\section{THE DOMESTIC PASSENGER FARE INVESTIGATION RATE-SETTING ADJUSTMENTS}

The DPFI was triggered in 1969 by Congressional complaints requesting a fare investigation to determine the reasonableness of costs and load factor in calculating the fare level. The General Passenger Fare Investigation (20 C.A.B. 291, 1960), had not decided these issues. As an interim action, the $\mathrm{CAB}$ required a mileage-based fare formula similar to American Airlines be adopted system-wide (Order 69-9-68). Order 70-2-121 set nine separate proceedings for hearing: Aircraft Depreciation, Leased Aircraft, Deferred Federal Income Taxes, Joint Fares, Discount Fares, Load Factor and Seating Configurations, Fare Level, Rate of Return, and Fare Structure. With Board decisions on each phase of the DPFI, less discretion was left to air carriers with regard to pricing, 
service, and structural initiatives that would not result in the disallowance of cost for rate-setting purposes. With the completion of the DPFI in 1974, the DPFI rate-setting procedures were an almost mechanical exercise designed to provide an analysis of passenger fare increase requests by air carriers without the $\mathrm{CAB}$ or its staff having to review a large number of rate-making decisions. Among other requirements, normal coach fares were to be offered on a formula rate, declining in cost-per-mile as distance increased; be based on a 55\% full-fare load factor, with discount passenger data adjusted to reflect carriage at full fares; and include disallowances for less than standard aircraft seating or aircraft utilization. ${ }^{3}$ Carriers were to be permitted a $12 \%$ rate-of-return (ROI) on their regulatory investment base, at the statutory $48 \%$ tax rate. As economic data had a reporting lag, costs were generally projected to a tariff's effective date. The effect of these economic adjustments for the year ended December 1977, projected to August 1, 1978, is shown in Table 1.

Table 1: Actual and DPFI Adjusted Data for the Year Ended December 1977

\begin{tabular}{|c|c|c|c|c|c|}
\hline & Actual & $\begin{array}{c}\text { Seats and } \\
\text { Utilization }\end{array}$ & $\begin{array}{c}\text { Discount } \\
\text { Fares }\end{array}$ & $\begin{array}{l}\text { Past Fare } \\
\text { Increases }\end{array}$ & $\begin{array}{c}\text { Cost } \\
\text { Escalation }\end{array}$ \\
\hline RPM’s (millions) & 127,008 & 127,008 & 120,312 & 114,866 & 114,866 \\
\hline ASM’s (millions) & 229,373 & 237,010 & 218,776 & 208,847 & 208,847 \\
\hline Load Factor (\%) & 55.37 & 53.59 & 54.99 & 55.00 & 55.00 \\
\hline Yield (Cents/RPM) & 8.623 & 8.623 & 8.996 & 9.623 & 9.623 \\
\hline Pass. Revenue & $\$ 10,952,162$ & $\$ 10,9652,162$ & $\$ 10,823,600$ & $\$ 11,053,797$ & $\$ 11,053,797$ \\
\hline Other Revenue & $\$ 170,063$ & $\$ 170,063$ & $\$ 170,063$ & $\$ 170,063$ & $\$ 170,063$ \\
\hline Operating Revenue & $\$ 11,122,227$ & $\$ 11,122,225$ & $\$ 10,993,663$ & $\$ 11,223,860$ & $\$ 11,223,860$ \\
\hline Capacity Expense & $\$ 7,092,108$ & $\$ 7,085,748$ & $\$ 6,614,835$ & $\$ 6,314,727$ & $\$ 6,736,573$ \\
\hline Non-Cap. Expense & $\$ 3,611,279$ & $\$ 3,611,279$ & $\$ 3,458,103$ & $\$ 3,311,101$ & $\$ 3,530,945$ \\
\hline Oper. Expense & $\$ 10,703,387$ & $\$ 10,697,027$ & $\$ 10,072,938$ & $\$ 9,625,828$ & $\$ 10,267,518$ \\
\hline Oper. Profit & $\$ 418,838$ & $\$ 425,198$ & $\$ 920,725$ & $\$ 1,598,032$ & $\$ 956,342$ \\
\hline Interest Expense & $\$ 186,990$ & $\$ 185,933$ & $\$ 172,738$ & $\$ 164,965$ & $\$ 164,965$ \\
\hline Earnings Before Tax & $\$ 231,848$ & $\$ 239,265$ & $\$ 747,987$ & $\$ 1,433,067$ & $\$ 791,377$ \\
\hline Tax at $48 \%$ & $\$ 111,287$ & $\$ 114,847$ & $\$ 359,034$ & $\$ 687,872$ & $\$ 379,861$ \\
\hline Net Income & $\$ 120,561$ & $\$ 124,418$ & $\$ 388,953$ & $\$ 745,195$ & $\$ 411,516$ \\
\hline Return Element & $\$ 307,551$ & $\$ 310,351$ & $\$ 561,689$ & $\$ 910,159$ & $\$ 576,480$ \\
\hline Investment & $\$ 5,992,117$ & $\$ 5,965,985$ & $\$ 5,550,489$ & $\$ 5,298,672$ & $\$ 5,298,672$ \\
\hline ROI (\%) & 5.1 & 5.2 & 10.1 & 17.2 & 10.9 \\
\hline
\end{tabular}

Source:U.S. Civil Aeronautics Board, Analysis of Domestic Trunk Performance in Accordance With the Standards Set Forth in the Domestic Passenger Fare Investigation, Year Ended December 1977. 
Note the results of these adjustments. Both traffic (RPM) and capacity (ASM) were reduced by about $10 \%$, yield was increased by a cent, operating expense reduced by about a billion dollars (before cost escalation), and ROI after cost escalation more than doubled. A fare increase request greater than about $1 \%$ would have been denied because the carriers did not meet efficiency standards, even though reported ROI was less than half the regulatory standard of $12 \%$.

\section{THE STANDARD INDUSTRY FARE LEVEL}

One of the requirements of the ADA in its phased implementation of airline deregulation was that the CAB had to establish a "Standard Industry Fare Level" based on fares in effect on July 1, 1979. The CAB was to periodically update the SIFL by the percentage change in unadjusted operating cost per available seat-mile. This essentially voided the extensive economic adjustments made to carrier operating results under the rate-setting policies of the DPFI in determining permissible fare increases prior to deregulation. The SIFL was to apply to all fare classes offered on July 1, 1977, but in practice was applied only to the unrestricted coach fare.

The SIFL is basically an index of unadjusted carrier operating cost per available seat-mile, with its base period the year ended July 1, 1979. There are no cost disallowances, revenue enhancements, or return on investment criteria as in the DPFI. The index is then applied to the DPFI fare formula of July 1, 1979, to determine the allowable ceiling fare. One important thing to remember, however, is that the DPFI formula effective on July 1, 1979, included all of the rate-making adjustments of the DPFI, which became imbedded in the SIFL. Leaving aside adjustments to expense, the regulatory yield, or formula rate, was $11.6 \%$ higher than reported yield (Table $1, \$ 0.09623 / \$ 0.08623$ ). In addition, the SIFL essentially was based on a regulatory ceiling fare level that represented an actual carrier return on regulatory investment of only $5.1 \%$.

However, because carriers need to cover average costs with average fares to remain in business, the SIFL and average yield closely track one another, as shown in Figure 6. Exceptions are limited. Yield was above the SIFL from 1980-1985, and significantly below the SIFL starting with the weakening of demand in 2000 and continuing with the loss of traffic, markedly reduced fares, and horrendous carrier losses following the terrorist attack in 2001.

Figure 6: Index of Yield per Passenger-Mile and the SIFL, 1979=1.00

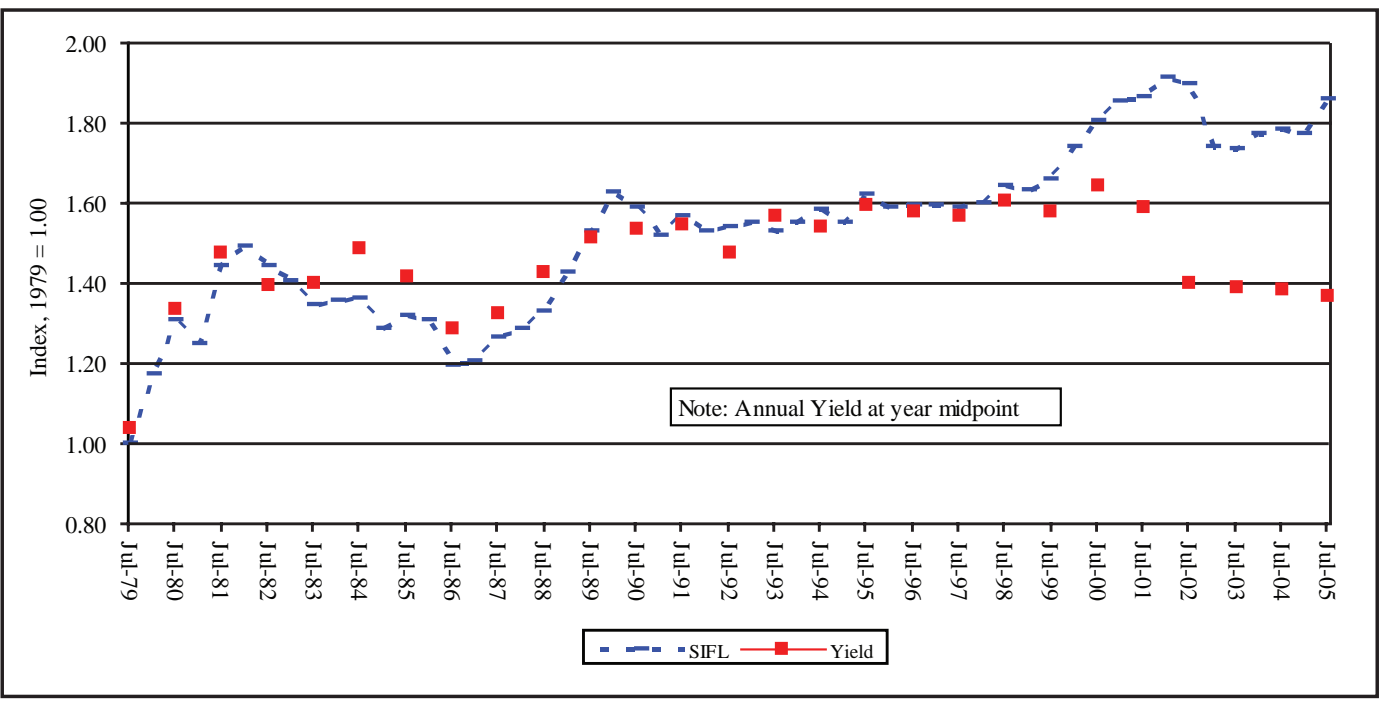

Source: U.S. Department of Transportation, Office of Domestic Aviation (http://www.ostpxweb.dot.gov/ aviation/domesticaffairs.htm\#sifl) 
Since the mileage-based fares under the SIFL were developed from the existing DPFI mileagebased fare formula, one can use the SIFL to estimate changes in carrier pricing that differ from the regulatory formula levels. One such methodology is shown below. It is not a complete "counterfactual" study, as it shows only annual passenger gains or losses in 1984 and 1988 and annual and second quarter results from 1997 to 2006, compared to the regulatory fare structure effective in 1979. A true counterfactual study would make the regulatory economic adjustments required under the DPFI and compare that to the current fare level.

The construction of passenger gains and losses uses only the SIFL and Origin-Destination Survey of Airline Passenger Traffic (Survey) data, both available electronically from the DOT's website, and the average 1979, 1984, and 1988 fare/SIFL data from the DOT's Secretary's Task Force on Competition in the U.S. Domestic Airline Industry (1990). While fare estimates incorporating the SIFL have previously been used in other studies to represent the coach fare, this study corrects for their misapplication of the SIFL as the average regulatory fare, and their failure to measure changes in fare differential by mileage interval. The results below are based upon the pre-deregulation relationship of average fares to the DPFI formula rate, by mileage interval.

The DPFI fare formula set unrestricted coach fares, with premium fares (first class) a percentage of coach. However, full coach fares also included night coach, Continental's "K" class fares, other unrestricted coach fares (intra-state), and children's and military fares. As a result, average full fares developed from carrier submissions (weighted by passenger-miles) under the DPFI were about 85\% of the DPFI formula rate as follows: $1976-84.5 \%, 1977-83.8 \%$, and 1978- 80.8\% (understated because of missing first class data). In 1977 discount fares, with an average stage length $50 \%$ longer than full fares, averaged less than $70 \%$ of the formula rate; the total average fare was about $80 \%$ of the formula rate.

While slightly higher, comparing average fares in 1979 by mileage interval from the survey to the SIFL supports an approximate 0.85 ratio of average fare to formula rate (1979 was the first year carriers reported fare data in the survey.) For comparative purposes, similar data are shown below for 1984 and 1988 from the U.S. DOT Competition Study (1990), and annual data for every second year from 1998-2004, plus 2005. Second quarter data from 1997-2006 are contained in the appendix. The weighted average is weighted by passenger-miles by mileage category. Weighting by passengers increases the weighted average by about five percentage points. For any particular mileage block there is no difference in effect between using passengers or passenger-miles.

Table 2: Ratio of Average Fares to SIFL by Mileage Block for Selected Annual Periods

\begin{tabular}{lcccccccc}
\hline Mileage Block & $\mathbf{1 9 7 9}$ & $\mathbf{1 9 8 4}$ & $\mathbf{1 9 8 8}$ & $\mathbf{1 9 9 8}$ & $\mathbf{2 0 0 0}$ & $\mathbf{2 0 0 2}$ & $\mathbf{2 0 0 4}$ & $\mathbf{2 0 0 5}$ \\
\hline $0-250$ & 0.976 & 0.946 & 1.362 & 1.381 & 1.403 & 1.169 & 1.325 & 1.331 \\
$251-500$ & 0.947 & 0.964 & 1.181 & 1.068 & 1.082 & 0.939 & 1.045 & 1.039 \\
$501-750$ & 0.966 & 1.132 & 1.169 & 1.083 & 1.063 & 0.902 & 0.961 & 0.952 \\
$751-1,000$ & 0.926 & 0.957 & 0.968 & 0.971 & 0.931 & 0.779 & 0.817 & 0.798 \\
$1,001-1,500$ & 0.850 & 0.800 & 0.837 & 0.880 & 0.847 & 0.689 & 0.697 & 0.670 \\
1,501-2,000 & 0.818 & 0.797 & 0.683 & 0.828 & 0.777 & 0.592 & 0.584 & 0.604 \\
Greater Than 2,000 & $\underline{0.729}$ & $\underline{0.762}$ & $\underline{0.612}$ & $\underline{0.824}$ & $\underline{0.787}$ & $\underline{0.543}$ & $\underline{0.510}$ & $\underline{0.538}$ \\
Weighted Avg. & 0.861 & 0.874 & 0.859 & 0.929 & 0.899 & 0.706 & 0.723 & 0.726 \\
\hline
\end{tabular}

Source: U.S. Department of Transportation, Secretary's Task Force on Competition in the U.S. Domestic Airline Industry, Pricing, Table I-5, and annual data developed from DB1 of the Survey. 
As indicated in Table 2, the ratio of the average fares to SIFL by mileage block changes markedly in the 10 years after deregulation. Under regulation, with the exception of first class fares, carriers could not offer fares above the formula rate. A ratio over 1.0, while theoretically possible, could only occur if there were a sufficiently high proportion of premium traffic to outweigh normal fares. Therefore, any ratio above 1.0 is an indication average fares are above regulatory ceiling levels. A ratio higher than that experienced in 1979 is an indication fares were higher than regulatory levels, and any ratio less than those shown in 1979 indicates a general reduction in fare level. Table 2 also indicates there were average fare premiums of between $6 \%$ and $40 \%$ in markets below 750 miles between 1988 and 2000.

The SIFL, however, being based on the DPFI fare taper, does contain a price bias. The DPFI fare formula deliberately under-priced short-haul fares and overpriced long-haul ones, and the successor SIFL would contain that same bias. Under regulation, carriers were able to offset the DPFI under-pricing of shorter-haul flights by restricting the use of discount fares and by having higher load factors (see Figure 12.4 of Morrison and Winston 1995). This may even have aided the under-pricing of long-haul flights, since the DPFI 55\% full-fare load factor standard was based on system data. In any case, that bias would have remained had regulation continued.

The basis of this paper is that any increase in the average fare/SIFL ratio after deregulation would reduce consumer welfare, any reduction would enhance it. Thus, according to Table 2, consumer welfare fell between 1979 and 2000 in markets below 1,000 miles, and generally rose in markets greater than 1,000 miles. There are mixed results after the terrorist attacks in 2001. By 2005 only markets under 500 miles were above the 1979 base ratio, with very significant reductions in many ratios. The weighted average ratio in 2005 is more than 20 percentage points below that of 1998 .

About half of all passengers transported between 1984 and 2000 were carried in distance intervals where the average fares were above constructed SIFL levels. Table 3 shows the percentage of passengers above SIFL for selected years and quarters. On an annual basis, the terrorist attacks in 2001 reduced the proportion of short-haul passengers carried above SIFL from 43.3\% in 2001 to only $5 \%$ in 2002 , and, while rebounding in 2003 , fell to about $25 \%$ in 2004 and 2005 . Quarterly passengers followed a similar pattern, with passengers paying above the SIFL rising to $40.9 \%$ of the total in the second quarter of 2006.

Table 3: Percent of Passengers Carried in Mileage Blocks Where the Average Fare was Above SIFL

\begin{tabular}{rccccccc}
\hline \multicolumn{4}{c}{ Annual Data } & \multicolumn{4}{c}{ Quarterly Data } \\
\hline \multirow{3}{*}{ Year } & $\%$ & Year & $\%$ & Year & $\%$ & Qnd \\
1979 & 0.0 & 1997 & 50.1 & 2002 & 5.0 & 2001 & 45.9 \\
1984 & 56.8 & 1998 & 49.6 & 2003 & 41.7 & 2002 & 5.0 \\
1988 & 50.6 & 1999 & 48.5 & 2004 & 24.9 & 2003 & 41.9 \\
& & 2000 & 47.2 & 2005 & 25.5 & 2004 & 24.8 \\
& & 2001 & 43.3 & & & 2005 & 25.9 \\
& & & & & & 2006 & 40.9 \\
\hline
\end{tabular}

Source: U.S. Department of Transportation, Secretary's Task Force on Competition in the U.S Domestic Airline Industry, Pricing, Table I-5, annual summary of quarterly data from the Origin-Destination Survey of Airline Passenger Traffic, Table 1, and Appendix. 
Passenger Fare Savings

Both traffic and yield fell precipitously after the terrorist attacks in 2001 (see Figures 9 and 10). Carriers were generally able to raise prices from their lows in 2000 in short-haul markets, likely due to the relatively high level of market concentration in those markets. Table 4 shows the weighted market share of the largest carrier in a market (Chicago-New York) and airport pair (Newark-O'Hare) for the second quarters of 2002, 2005, and 2006. Concentration in both city and airport pairs has increased for markets over 1,000 miles from 2002 to 2006, with airport pairs significantly more concentrated overall.

Table 4: Weighted Market Share of the Largest Carrier in a Market, Selected Quarterly Periods

\begin{tabular}{lccc|ccc}
\hline Mileage Interval & \multicolumn{3}{c|}{ City-Pairs } & \multicolumn{3}{c}{ Airport-Pairs } \\
\hline & $2 \mathrm{Q} 2002$ & $2 \mathrm{Q} 2005$ & $2 \mathrm{Q} 2006$ & $2 \mathrm{Q} 2002$ & $2 \mathrm{Q} 2005$ & $2 \mathrm{Q} 2006$ \\
$0-250$ & 63.3 & 62.8 & 62.8 & 75.3 & 77.7 & 80.8 \\
$251-500$ & 71.8 & 71.5 & 71.1 & 80.3 & 77.7 & 79.3 \\
$501-750$ & 59.0 & 58.0 & 55.7 & 65.5 & 64.1 & 65.7 \\
$751-1,000$ & 58.4 & 55.1 & 55.0 & 65.1 & 65.8 & 66.6 \\
$1,001-1,500$ & 51.0 & 53.3 & 55.4 & 61.9 & 63.8 & 65.8 \\
$1,501-2,000$ & 48.4 & 49.5 & 51.9 & 54.5 & 59.2 & 64.3 \\
Greater Than 2,000 & $\underline{40.0}$ & $\underline{44.7}$ & $\underline{46.5}$ & $\underline{49.6}$ & $\underline{54.3}$ & $\underline{60.1}$ \\
Total & 57.3 & 57.2 & 57.5 & 64.9 & 65.7 & 68.0 \\
\hline
\end{tabular}

Source: U.S. Department of Transportation Origin-Destination Survey of Airline Passenger Traffic, Table 1, 1A. Selected quarters are from (www.ostpxweb.dot.gov/aviation/X-50\%20Role_files/ consumerairfaresreport.htm).

The relationship of SIFL formula rates to carrier pricing is complex, and includes a carriers' pricing philosophy as well as cost structure and competition. The tables below compare Southwest's and American's relationship of airport-pair fares to SIFL fares by mileage interval where each carrier is the carrier with the largest market share. Only airport-pairs with greater than 10 passengers per day and only distance intervals in which there are at least five markets are included.

Table 5: Comparison of Southwest's Airport-Pair Fares to SIFL by Mileage Block

\begin{tabular}{lrccccc}
\hline Mileage Interval & $\begin{array}{c}\text { Daily } \\
\text { Pass. }\end{array}$ & $\begin{array}{c}\text { Airport-Pair } \\
\text { Markets }\end{array}$ & $\begin{array}{c}\text { Weighted } \\
\text { Apt. Share }\end{array}$ & $\begin{array}{c}\text { Average } \\
\text { Fare }\end{array}$ & $\begin{array}{c}\text { SIFL } \\
\text { Fare }\end{array}$ & $\begin{array}{c}\text { \% Diff. } \\
\text { from SIFL }\end{array}$ \\
\hline $0-250$ & 9,574 & 13 & 95.6 & $\$ 97.17$ & $\$ 82.62$ & 17.6 \\
$251-500$ & 12,235 & 28 & 96.2 & $\$ 98.63$ & $\$ 112.59$ & -12.4 \\
$501-750$ & 6,038 & 26 & 90.4 & $\$ 133.24$ & $\$ 160.49$ & -17.0 \\
$751-1,000$ & 6,324 & 27 & 75.4 & $\$ 127.99$ & $\$ 203.60$ & -37.1 \\
$1,001-1,500$ & 7,654 & 42 & 80.2 & $\$ 144.20$ & $\$ 255.21$ & -43.5 \\
$1,501-2,000$ & 4,962 & 22 & 92.5 & $\$ 149.64$ & $\$ 326.06$ & -54.1 \\
Greater Than 2,000 & $\underline{\text { N/A }}$ & $\underline{\text { N/A }}$ & $\underline{\text { N/A }}$ & $\underline{\text { N/A }}$ & $\underline{\text { N/A }}$ & $\underline{\text { N/A }}$ \\
Total & 46,787 & 158 & 89.5 & $\$ 119.63$ & $\$ 170.91$ & -19.7 \\
\hline
\end{tabular}


Table 6: Comparison of American's Airport-Pair Fares to SIFL by Mileage Block

\begin{tabular}{|c|c|c|c|c|c|c|}
\hline Mileage Interval & $\begin{array}{l}\text { Daily } \\
\text { Pass. }\end{array}$ & $\begin{array}{l}\text { Airport-Pair } \\
\text { Markets }\end{array}$ & $\begin{array}{l}\text { Weighted } \\
\text { Apt. Share }\end{array}$ & $\begin{array}{c}\text { Average } \\
\text { Fare }\end{array}$ & $\begin{array}{l}\text { SIFL } \\
\text { Fare }\end{array}$ & $\begin{array}{c}\% \text { Diff. } \\
\text { from SIFL }\end{array}$ \\
\hline $0-250$ & 2,627 & 23 & 86.7 & $\$ 119.47$ & $\$ 81.95$ & 45.8 \\
\hline $251-500$ & 5,193 & 29 & 73.6 & $\$ 148.71$ & $\$ 116.62$ & 27.5 \\
\hline $501-750$ & 8,036 & 47 & 68.3 & $\$ 189.11$ & $\$ 164.91$ & 14.7 \\
\hline $751-1,000$ & 10,200 & 54 & 69.2 & $\$ 213.13$ & $\$ 202.15$ & 5.4 \\
\hline $1,001-1,500$ & 24,240 & 90 & 66.1 & $\$ 211.12$ & $\$ 254.77$ & -17.1 \\
\hline $1,501-2,000$ & 4,475 & 47 & 60.0 & $\$ 247.76$ & $\$ 325.55$ & -23.9 \\
\hline Greater Than 2,000 & $\underline{4,209}$ & $\underline{33}$ & $\underline{82.0}$ & $\$ 325.50$ & $\$ 444.45$ & $\underline{-26.8}$ \\
\hline Total & 58,980 & 323 & 69.2 & $\$ 209.83$ & $\$ 232.47$ & -9.7 \\
\hline
\end{tabular}

Source: U.S. Department of Transportation, Office of Domestic Aviation, Second Quarter, 2006, Table 1A (http://www.ostpxweb.dot.gov/aviation/X-50\%20Role_files/consumerairfarereport.htm).

Southwest's philosophy of basically unrestricted low fares and use of less-congested airports allows it to reduce costs and monopolize airport-pair markets. Compare airport-pair concentration levels between Southwest and the industry in Tables 4 and 5 and American in Tables 4 and 6 . Southwest's weighted ratio of its fares to SIFL is $-19.7 \%$, not much below the $-15 \%$ difference shown under regulation. Southwest's airport-pair concentration level is more than 20 percentage points higher than American's or the industry.

\section{CONSTRUCTION OF PASSENGER SAVINGS AND COMPARISON TO DOMESTIC MAJOR PASSENGER CARRIER OPERATING PROFIT AND LOSS}

Shown above are differences in fares by percentage and level by mileage block from the SIFL and market concentration and fare levels for two diverse air carriers from the survey. Changes in the ratio of actual fares to SIFL will be used to estimate passenger savings between 1979 and selected periods in two stages. First, passenger savings will be estimated by using the difference between actual fares and the SIFL. That savings will be adjusted by the difference between the DPFI formula rate and the actual fares under regulation. Both the passenger savings and adjusted passenger savings use average fares and sample passengers from the survey by mileage interval. Figure 7 shows the annual sum of the adjusted passenger gain or loss for all mileage blocks for the top 1,000 city-pairs for 1984, 1988, and 1998-2005, compared to domestic major air carrier operating profit or loss for the same period. Annual survey data is the sum of the reported quarterly data, except for 1984 and 1988 which are from the competition study.

Annual adjusted passenger savings are shown to be inversely related to domestic major carrier operating profit. Using second quarter data (the second quarter of the year most closely corresponds to yearly data) to show the effects of the carrier fare increases in 2005 and 2006 supports this inverse relationship between carrier profit and adjusted consumer savings (Figure 8). Quarterly passenger fare saving and loss computations are contained in the appendix.

The factors that turned a consumer loss of $\$ 1$ billion a quarter in 2000 into a gain of $\$ 700$ million in 2001, and nearly double that through 2005, were the initial reduction of demand in 2000, and the very marked fall in passenger numbers and fare levels after the terrorist attacks on September 11, 2001. Below are shown the origin-destination passengers (Figure 9) and the ratio of actual passenger fares to the SIFL (Figure 10) for selected second quarters between 2000 and 2006, and including 1979 as a reference base for the SIFL ratio.

Note that the shorter-haul passengers (0-750 miles) in 2002, 2004 and 2006 are below the 2000 levels, and most remain below up to 1,000 miles. Longer-haul passengers partially recovered in 2002, and are markedly higher in 2004 and 2006 in markets over 1,000 miles than in 2000. 
Figure 7: Annual Adjusted Passenger Fare Savings and Domestic Major Passenger Carrier Operating Profit or Loss, 1984, 1988, and 1997-2005 (millions of dollars)

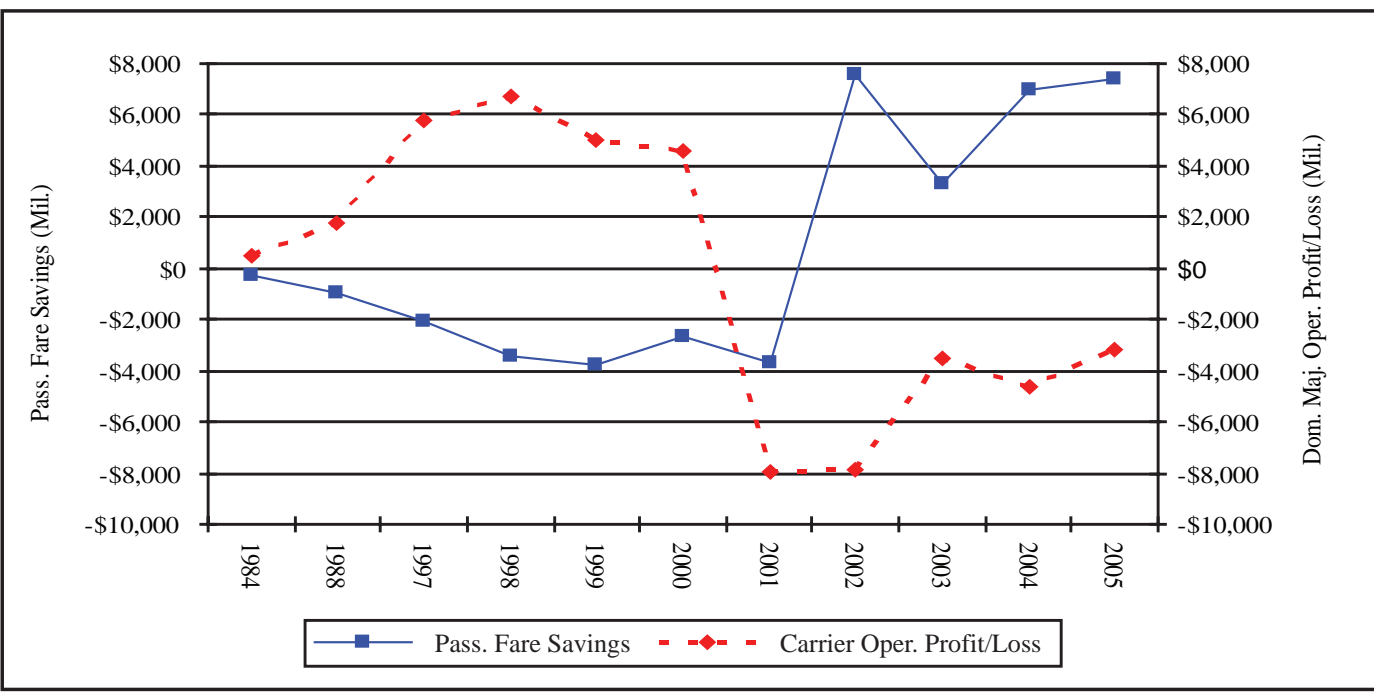

Source: Appendix and U.S. Department of Transportation Airline Quarterly Financial Review, selected issues.

Figure 8: Adjusted Passenger Fare Savings and Domestic Major Carrier Operating Profit or Loss, Second Quarter 1997-2006 (millions of dollars)

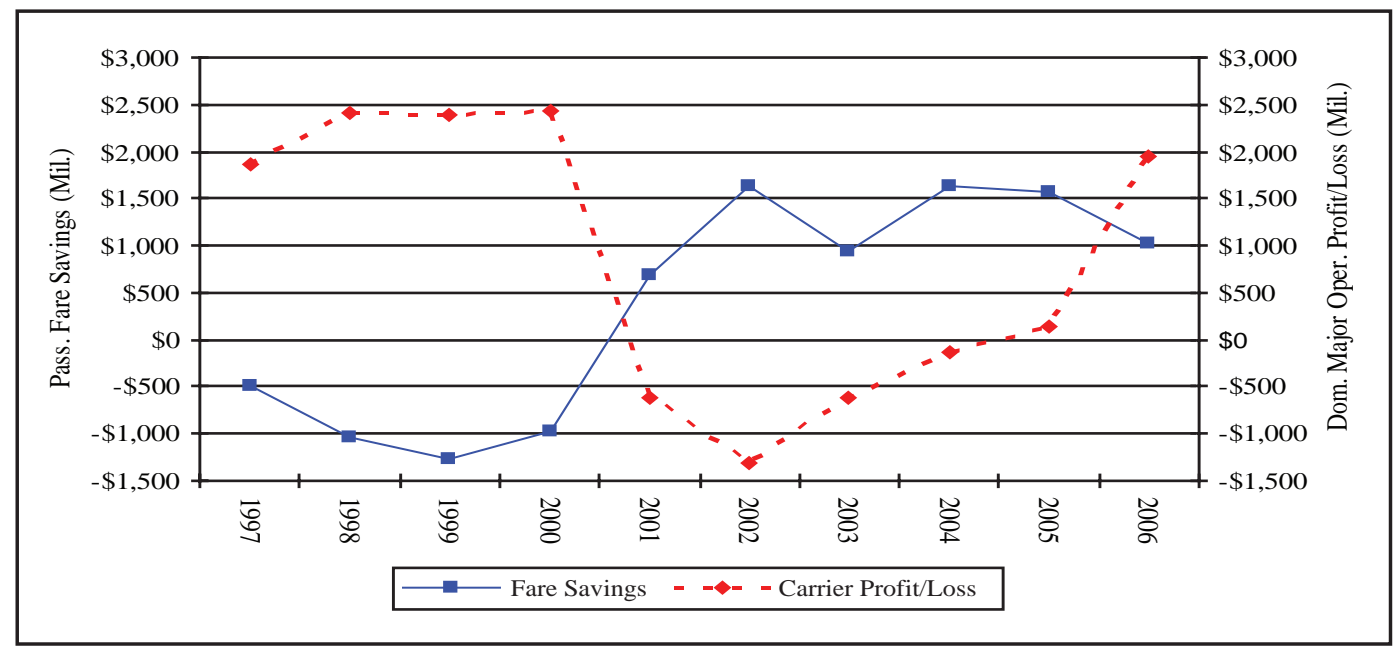

Source: Appendix and U.S. Department of Transportation Airline Quarterly Financial Review, selected issues.

The three years prior to the terrorist attacks, 1998, 2000, and the reference year 1979 are shown with solid lines. 2002, 2004, and 2006 have broken lines. Note the marked structural shift in the ratio after 2000. While all fares fell in 2002 compared to the SIFL, long-haul fares fell disproportionately, and did not recover as readily. Because fewer short-haul passengers were carried at a premium (and more under-priced long-haul passengers were carried), the previous cross-subsidy from highfare concentrated short-haul markets to more competitive long-haul markets failed, and the carriers incurred huge losses. Those under-priced long-haul markets, however, generated considerable passenger savings (Figure 5). In 2006, the fare/SIFL ratio surpassed previous highs below 500 
Figure 9: Second Quarter Origin-Destination Passengers By Mileage Block, Selected Years

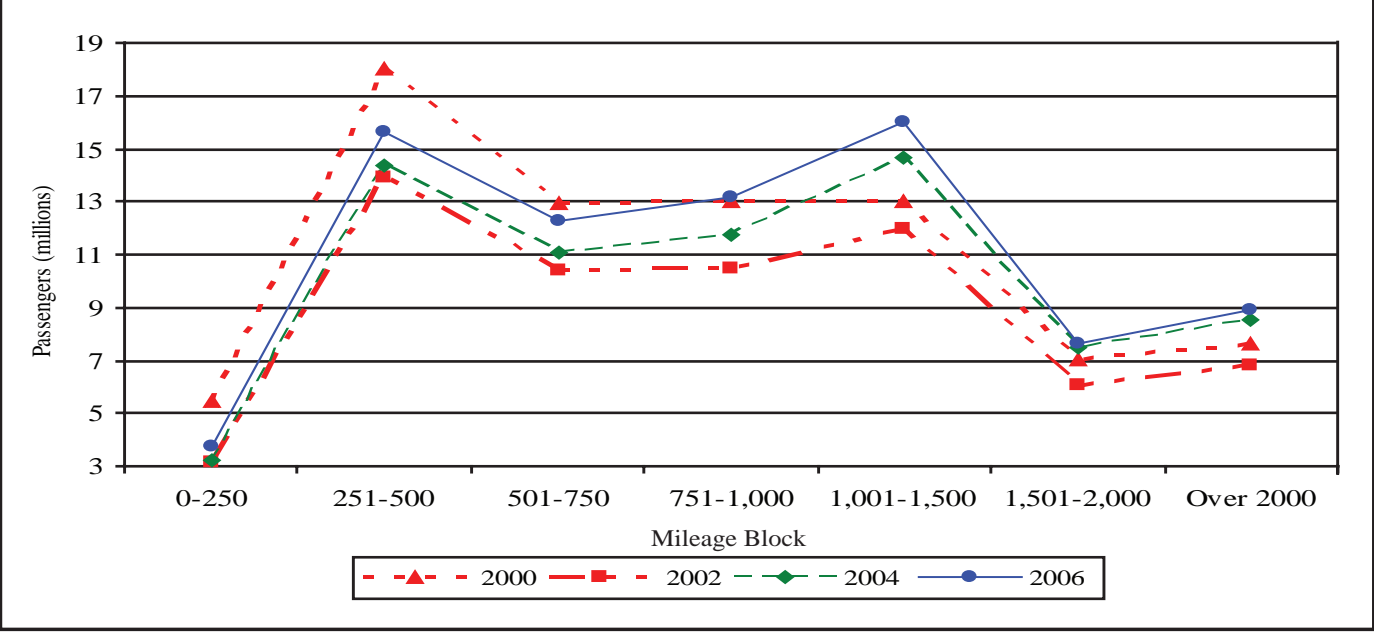

Source: Appendix.

Figure 10: Ratio of Average Fare to SIFL by Mileage Block, Second Quarter, Selected Years

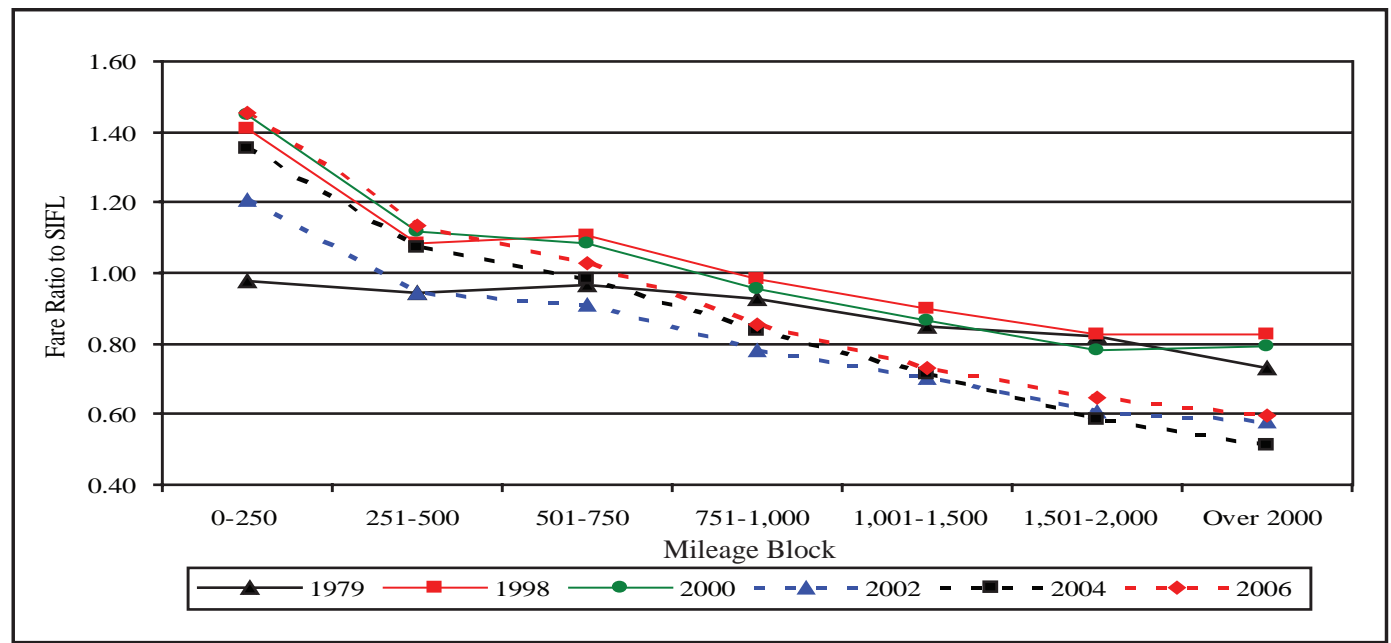

Source: Appendix.

miles, with smaller upward shifts in all other mileage categories from the low levels following the terrorist attacks in 2001. They have not recovered sufficiently in markets over 1,000 miles to allow recovery of costs.

\section{DIFFERENCES FROM OTHER STUDIES SHOWING LARGE CONSUMER SAVINGS}

Most other studies showing the effect of deregulation on consumer welfare basically conclude that there are considerable passenger price savings due to the effects of increased competition (number of competitors), gains in productivity (output/employee), and efficiency (load factor). Offering comments on this collection of studies is not realistic. The comments below address specific problems in the construction of passenger fare savings in one of the most quoted works, Morrison and Winston (1995), and a well-written draft paper likely to be published later in 2007 by Borenstein and Rose. 
While Morrison and Winston (1995) present their counterfactual overall passenger fare savings of $\$ 12$ billion per year in 1993 dollars on page 82, their fare savings methodology is presented in pages 11-14. The authors first adopt the post-deregulation SIFL fare formula as the basis for regulated fares. They then assume that deregulation increased productivity $1.2 \%$ a year, based on productivity changes between 1976 and 1983 developed by Caves et al. (1987). The actual SIFL was then increased by this $1.2 \%$ a year from 1976 to 1983 to remove this purported benefit of deregulation. (1983 was evidently the midpoint of the 1979-1993 estimating period, and the 1.2\% annual productivity increase to the SIFL $(8.7 \%$ by 1983$)$ was then stopped to "...err on the side of conservatism.”) Though not stated, it appears the $8.7 \%$ productivity offset was continued from 1983 through 1993. This increased SIFL fare formula is used to construct regulated fares from the same passenger data base used to construct actual yield (U.S. Department of Transportation, OriginDestination Survey of Airline Passenger Traffic). No data are presented, and the study results cannot be replicated.

There are several obvious problems: the use of a productivity offset; the failure to recognize that the precursor DPFI formula to the SIFL was not the selling fare but a ceiling fare; pre-dating the SIFL to 1976; and not recognizing the change in passenger mix by distance over time. Dealing with productivity first, the authors evidently did not recognize that productivity increases are more likely to be affected by increases in aircraft size than changes in carrier operations. Domestic average aircraft seats per mile increased $21.1 \%$ between 1976 and 1983 . The peak year for average domestic aircraft size was 1983; size has declined every year since then. Since the book was printed in 1995, actual productivity figures could have been used for the entire study period 1979-1993. However, those purported significant increases in productivity due to deregulation disappeared after 1983 with the start of the reduction in aircraft size. See Figure 5 above, where changes in average seats per aircraft mile and ASM/employee are compared, and the recent study of productivity by the U.S. Government Accountability Office, GAO-06-630, (2006) (Figure 6).

In addition, part of that productivity increase would have been captured under regulation through the rate-making adjustments of the DPFI, and would have served to reduce the regulatory fare level. This adjustment is counter-intuitive in any case, since the hub-spoke systems developed under deregulation are more labor intensive than linear systems. There should be no "productivity" adjustment to the SIFL.

The SIFL, as an extension of the DPFI fare formula, represents the coach ceiling fare. Average full fares under the DPFI were about 15\% below the formula rate (See Table 2, above). Use of the SIFL formula to represent the regulatory fare level thereby overstates that fare level by a minimum of 15\%. Morrison and Winston's (1995) study now contains two positive structural biases for the regulatory fare estimate: the SIFL offset for a productivity increase (8.7\%) and the difference between charged and ceiling formula rates (15\%).

Finally, the SIFL did not exist until Order 79-6-96 was issued (U.S. Civil Aeronautics Board 1979). Increasing the SIFL was not possible prior to that date. Fare increases allowed by the CAB through May 1979 were under the DPFI, and included significant regulatory cost disallowances, including that for discount fares. Increases in discount traffic under the DPFI would depress the ceiling fare level unless those discounts could overcome the generation/diversion adjustments. It is disingenuous to suggest that more discount fares immediately before deregulation would increase the regulatory ceiling fare formula. Because no data were presented, the effect of this miscalculation is unknown, but it is the third bias in the study increasing the "regulated" fare level. (The shift in passenger mix by distance will be ignored, since developing a true counterfactual passenger mix is beyond the scope of this paper.)

Borenstein and Rose (forthcoming) also base their counterfactual estimate of regulated fare levels on the SIFL. They also use the actual passengers and fares reported in the DOT's O-D Survey, DB1A, and construct a counterfactual fare estimate using the SIFL fare formula. For 2005, they estimate that consumers saved some $\$ 28$ billion, with fares some 30\% below regulatory levels (see their page 12 and Figure 4). 
While a more straight-forward approach than that followed by Morrison and Winston (1995), there are some similar problems. First, as with Morrison and Winston (1995), they equate the SIFL formula with the regulatory fare level. As previously indicated, the DPFI formula overstates the average regulated full fare by some $15 \%$, and overstates formula yield to actual yield by about $20 \%$. In addition, the abrupt change in passenger mix after the terrorist attacks (less short-haul passengers paying premiums and more long-haul ones well below cost) distorts fare comparisons after 2001. This is evident in the significant widening of the SIFL/actual fare gap in their Figure 4. While the percentage difference in the Borenstein and Rose study between actual and SIFL formula yield (30\%) agrees with that of the methodology adopted in the appendix for annual data (a ratio of .705 actual/formula revenues) in 2005, the level of the savings does not. ${ }^{4}$

This is due to a larger passenger base in Borenstein and Rose (Borenstein and Rose use the entire DB-1 of the Origin-Destination Survey of Airline Passenger Traffic, the appendix uses the largest 1,000 market subset from DB-1, available on DOT's webpage), and the use of a -1.5 demand elasticity adjustment. A -1.5 price elasticity for airline travel is very high, and likely unrealistic. ${ }^{5}$

Borenstein and Rose do, however, recognize that there are weaknesses in developing a true counterfactual against which to judge airline deregulation. They recognize the differing effects productivity and changes in load factor may have had on the SIFL and counterfactual economic results. More importantly, they recognize that it is possible airline regulation would have evolved, similar to electricity regulation. (See their discussion of these issues on pages 12 and 13.)

It is likely service restrictions would have been eased and there would have been some accommodation for differing service quality/fare tradeoffs. On the other hand, some decisions by the pro-deregulation CAB in the late 1970s presaged the undercutting of long-haul nonstop service pricing so prevalent in today's hub-spoke system (Texas International's "Peanuts" fares, Order 77-2133), and offset the regulatory flexibility inherent in the DPFI to accept different rate-setting criteria (Delta's “Aerobus” fares, Order 77-11-124).

\section{CONCLUSION}

This paper makes clear that the grant of pricing freedom to the airline industry has generally resulted in average prices being higher than they would have been had regulation continued under the DPFI rate-setting policies. It is also clear that the terrorist attacks caused air carriers to sufficiently reduce fares to attract passengers and that there have been considerable passenger savings, albeit with large air carrier losses. However, significant structural changes have also occurred in air carrier operations and pricing since the terrorist attacks. It is not yet clear whether these changes will result in continued consumer savings, or whether the significant increases in fares over the past year (second quarter 2006 yield is up 9.8\% from 2005 for the domestic majors), will allow carriers to continue their return to the relationships between fares and SIFL established shortly after deregulation. Should they be able to re-establish their old pattern of pricing, the passenger benefits of recent years will be reduced or eliminated.

\section{Endnotes}

1. In long-term trend analysis, one is generally interested in whether growth rates are increasing or declining. An arithmetic graph increases in scale by a fixed amount, such that an increase from 10 to 100 and 100 to 1,000 will show markedly different effects in level, even though the rate of growth is the same. A logarithmic graph shows equal vertical distance on the graph for equal percentage changes in growth, in which significant increases in level may not equate to marked increases in growth rates. In aviation, there was no increase in growth rates with deregulation, though the level did increase significantly. This is best illustrated by the use of a logarithmic graph. 
Passenger Fare Savings

2. The CAB immunized Mutual Aid Pact (Pact) permitted participating air carriers (basically all trunk lines except Delta) to pay to a struck carrier the difference between its increased revenue received during that strike and applicable direct expenses incurred. Revisions to the Pact eventually guaranteed a minimum payment to a struck carrier of a specific portion of its normal operating expenses. Several air carriers, most notably Northwest and National, took repeated strikes, and had among the lowest labor expenses of the trunklines. The ability of air carriers to receive a cross-subsidy when struck was well recognized by labor unions.

3. The most severe of the rate-making adjustments was for discount fares. As the DPFI was essentially developed to control prices of full-fare traffic, the discount fare adjustment used a generation/diversion methodology to estimate what portion of discount traffic was diverted from full fares, and what portion was newly generated. This "break-even” percentage applied a yield elasticity estimate of -0.7 as follows: Breakeven Percentage $=1$-(Ratio) / 1-.3(Ratio), where Ratio equaled the ratio of actual discount fare yield to the full-fare yield at the discount fare mileage. The Breakeven Percentage was then applied to the total discount traffic, separating it into generated and diverted portions. Generated traffic was removed, and associated revenue, expense, tax, and return elements were adjusted.

4. Table 1 (top 1,000 market-pairs) of the Origin-Destination Survey of Airline Passenger Traffic on DOT's website contains 795,897 average daily passengers for the fourth quarter of 2005 . Table 6, all markets with at least 10 daily passengers, contains 6,566 pairs and 1,041,754 average daily passengers. There are 2,908 excluded markets, containing some 226,440 passengers. Table 1 's ratio to the total is $62.8 \%$. That ratio, applied to the $\$ 16.1$ billion annual fare savings for Table 1 passengers in 2005, would increase the approximate current-dollar passenger savings in this paper to about $\$ 25.6$ billion, before adjustment for the 1979 ratio of fares to SIFL.

5. On a domestic system basis, air travel is not shown to be price-elastic. Using an additive regression form with RPM's as the dependent variable and real GDP and Yield as independent variables (1965-2004), the resulting equation is RPM's = 6.63 + 0.903RGDP- 2.527RYield; $\mathrm{R}^{2} \mathrm{adj}=97.71 ; \mathrm{DW}=0.332$. Correcting for serial correlation through the use of first-differences, using a multiplicative regression form, and reducing the time period to 1980-2000 results in: dLogRPM's= -7.702 + 1.154dLogRGDP - 0.488dLogRYield; $\mathrm{R}^{2} \mathrm{adj}=64.8, \mathrm{DW}=1.727$. Other formulations using different measures of wealth (disposable personal income, non-farm employment) and time intervals show similar results. Some markets may have fare elasticities greater than 1.0, the industry does not. The CAB used an elasticity estimate of -0.7 in adjusting discount passengers to full-fare levels in the DPFI.

\section{References}

Air Transport Association. Washington, D.C. Various website sub-addresses at (www.airlines. org).

Borenstein, Severin and Nancy Rose. How Airline Markets Work, Or Do They?: Regulatory Reform in the Airline Industry. Working paper for a forthcoming National Bureau of Economic Research volume on regulatory reform.

Caves, Douglas W., Laurits R. Christensen, Michael W. Tretheway, and Robert J. Windle. "An Assessment of the Efficiency Effects of U.S. Airline Deregulation via an International Comparison.” Elizabeth E. Bailey ed. Public Regulation: New Perspectives on Institutions and Policies. Cambridge, MA: MIT Press (1987): 285-320. 
Morrison, Steven A. and Clifford Winston. The Evolution of the Airline Industry. The Brookings Institution,. Washington, D.C. 1995.

U.S. Civil Aeronautics Board. General Passenger Fare Investigation. 20 C.A.B. 291, Washington, D.C., 1960.

U.S. Civil Aeronautics Board. Domestic Passenger Fare Investigation, January 1970 to December 1974. U.S. Government Printing Office, Washington, D.C., 1975.

U.S. Civil Aeronautics Board. Analysis of Domestic Trunk Performance in Accordance With the Standards Set Forth in the Domestic Passenger Fare Investigation. Washington, D.C. Unpublished library reference works, various dates.

U.S. Civil Aeronautics Board. Establishment of the Interim Standard Industry Fare Level. Order 79-6-96. Washington, D.C., 1979

U.S. Congress. Airline Deregulation Act of 1978. Public Law 95-504, October 24, 1978. Washington, D.C. See particularly sections [1002d (6) (A) and (6) (B)].

U.S. Department of Transportation. Origin-Destination Survey of Airline Passenger Traffic. Selected quarters. Washington, D.C. See also the reduced form in www.ostpxweb.dot.gov/aviation/ X-50\%20Role_files/consumerairfaresreport.htm.

U.S. Department of Transportation. Airline Quarterly Financial Review. Selected issues. Washington, D.C. (www.ostpxweb.dot.gov/aviation/airlinefinancialreview.htm)

U.S. Department of Transportation. Secretary's Task Force on Competition in the U.S. Domestic Airline Industry. Washington, D.C., February 1990. See particularly Pricing, Volume I and II.

U.S. Government Accountability Office. Reregulating the Airline Industry Would Likely Reverse Consumer Benefits and Not Save Airline Pensions. GAO-06-630. Washington, D.C., June 2006. (www.gao.gov/cgi-bin/getrpt?GAO-06-630)

David B. Richards is retired after service at the Civil Aeronautics Board, the DOT's Office of the Secretary (OST), and the Federal Aviation Administration. While at the CAB, he did the ratesetting calculations for the DPFI and Class Rate IX of the Local Service Class Subsidy Rate, wrote many orders disposing of passenger fare filings, and developed and updated the SIFL. For OST, he completed major sections of the competition study, including pricing, and was part of the Airline Stabilization Act Compensation Team that distributed the $\$ 5$ billion in compensation for air carrier losses following the terrorist attack in 2001. At the FAA, his primary work was on performance metrics, and was a member of the team that issued the initial report on airport capacity. 


\section{APPENDIX}

METHODOLOGY FOR DETERMINING CONSUMER GAIN OR PREMIUM BY PERIOD

A Comparison of Current Fares to the Fare Structure Effective in 1979

Quarterly Data from Origin-Destination Survey of Airline Passenger Traffic, Top 1,000 City-Pairs

The Consumer Gain or Premium for any mileage interval by period after deregulation is determined by comparing the actual fare to the SIFL fare, and multiplying the difference by the passengers in the distance interval. The pre-deregulation Gain or Premium by mileage block is determined by multiplying the SIFL fare by the 1979 fare/SIFL ratio, constructing a regulatory average fare, and multiplying the difference between the SIFL and that constructed fare by the passengers in the distance interval. The pre-deregulation Gain or Premium is then subtracted from the post-

deregulation Gain or Premium to determine the net effect of airline deregulation.

Quarterly Data: Second Quarter for each year 1997-2006

$\begin{array}{llll}\text { Distance Interval } & \underline{0-250} & \mathbf{2 5 1 - 5 0 0} & \underline{501-750} \\ \text { A.1. } 2006 \text { GAIN OR LOSS AT } 2006 \text { RATIO OF ACTUAL FARE TO SIFL (Second Quarter) }\end{array}$

Avg. Distance

Avg. Fare

$\begin{array}{llll}218 & 372 & 629 & 884\end{array}$

SIFL Fare

Ratio: Avg. Fare/SIFL Fare

$\$ 120.61 \quad \$ 130.10$

$\$ 166.20 \quad \$ 172.24$

$\$ 83.00 \quad \$ 114.89 \quad \$ 161.77$

$\$ 202.03$

$\begin{array}{llll}1.45317 & 1.13238 & 1.02739 & 0.85253\end{array}$

Difference: Avg. Fare less SIFL Fare

$\$ 37.61 \quad \$ 15.21$

$\$ 4.43 \quad-\$ 29.79$

Passengers

$3,782,663 \quad 15,598,164$

Wtd. Premium (\$000) 1/

$\$ 142,274 \quad \$ 237,229$

$\$ 54,237 \quad-\$ 391,482 \quad-\$ 1,080,222$

$\$ 180.80$

$\$ 248.14$

0.72862

$-\$ 67.34$

$\$ 1,080,222$

A.2. 2006 GAIN OR LOSS AT 1979 RATIO OF ACTUAL FARE TO SIFL (Second Quarter)

1979 Farel $0.97630-0.94665$ (SECONd QUarte)

Difference from SIFL 2/

$\begin{array}{rrrr}\$ 81.03 & \$ 108.76 & \$ 156.21 & \$ 186.99 \\ -\$ 1.97 & -\$ 6.13 & -\$ 5.56 & -\$ 15.04\end{array}$

Wtd. Premium $\$(000) 3 /$

$-\$ 7,442 \quad-\$ 95,611 \quad-\$ 68,063 \quad-\$ 197,659$

0.85024

$\$ 210.98$

$-\$ 37.16$

2005 Pass. Penalty $\$(000) 4$

$\$ 149,716 \quad \$ 332,840 \quad \$ 122,299 \quad-\$ 193,822$

$\$ 484,089$

B.1. 2005 GAIN OR LOSS AT 2005 RATIO OF ACTUAL FARE TO SIFL (Second Quarter)

Avg. Distance

Avg. Fare

SIFL Fare

Ratio: Avg. Fare/SIFL Fare

Difference: Avg. Fare less SIFL Fare

Passengers

Wtd. Premium (\$000) $1 /$
219
$\$ 106.58$

$\$ 77.39 \$ 106.66$

$1.37719 \quad 1.06840$

$\$ 29.19 \quad \$ 7.30$

$4,168,082$

$\$ 121,669$
$\$ 7.30$
$, 688,345$
11,83

$\$ 114,453$
$\$ 146.57 \quad \$ 153.34$

$\$ 150.15 \quad \$ 187.88$

$0.97613 \quad 0.81615$

$-\$ 3.58 \quad-\$ 34.54$

$11,837,180 \quad 12,850,884$

$-\$ 42,420 \quad-\$ 443,885$
$627 \quad 884$
1,175

$\$ 159.76$

$\$ 230.60$

0.69280

$-\$ 70.84$

$15,699,211$

$-\$ 1,112,132$ $\underline{1,501-2,000}$

1,732

$\$ 216.28$

$\$ 334.52$

0.64654

$-\$ 118.24$

$7,647,908$

$-\$ 904,270$
Over 2000

2,362

$\$ 255.77$

$\$ 430.15$

0.59460

$-\$ 174.38$

$8,902,626$

$-\$ 1,552,454$
$0.81838 \quad 0.72931$

$\$ 273.76 \$ 313.71$

$-\$ 60.76 \quad-\$ 116.44$

$-\$ 464,650 \quad-\$ 1,036,598$

$-\$ 439,621 \quad-\$ 515,856$

$-\$ 2,466,155$

$-\$ 1,028,532$

$\begin{array}{rrr}1,734 & 2,361 & \\ \$ 192.46 & \$ 221.94 & \\ \$ 311.35 & \$ 399.88 & \\ 0.61815 & 0.55501 & 0.72473 \\ -\$ 118.89 & -\$ 177.94 & \\ 7,635,874 & 8,734,599 & 76,614,174 \\ -\$ 907,835 & -\$ 1,554,262 & -\$ 3,824,413\end{array}$

B.2. 2005 GAIN OR LOSS AT 1979 RATIO OF ACTUAL FARE TO SIFL (Second Quarter)

2005 Fare at 1979 Fare/SIFL Ratio 5/ $\quad \$ 75.55 \quad \$ 100.97 \quad \$ 144.99 \quad \$ 173.89$

Difference from SIFL 2/

$\begin{array}{rrrr}\$ 75.55 & \$ 100.97 & \$ 144.99 & \$ 173.89 \\ -\$ 1.83 & -\$ 5.69 & -\$ 5.16 & -\$ 13.99\end{array}$

$\begin{array}{rrrr}-\$ 1.83 & -\$ 5.69 & -\$ 5.16 & -\$ 13.99 \\ -\$ 7,646 & -\$ 89,278 & -\$ 61,093 & -\$ 179,772\end{array}$

0.85024

$\$ 196.06$

$-\$ 34.54$

$-\$ 542,183$

$\$ 129,315 \quad \$ 203,730 \quad \$ 18,674 \quad-\$ 264,113$

$-\$ 569,949$

$0.81838 \quad 0.72931$

$\$ 254.80 \quad \$ 291.64$

$-\$ 56.55 \quad-\$ 108.24$

$-\$ 431,790 \quad-\$ 945,468$

2005 Pass. Penalty $\$(000) 4 /$

OF ACTUAL FARE TO SIFL (Second Quarter)

$\begin{array}{lccc}\text { C.1. } 2004 \text { GAIN OR LOSS AT 2004 RATIO OF ACTUAL FARE TO SIFL (Second Quarter) } \\ \text { Avg. Distance } & 216 & 366 & 628\end{array}$

Avg. Fare

$\begin{array}{rrrr}216 & 366 & 628 & 884 \\ \$ 104.00 & \$ 113.26 & \$ 147.94 & \$ 156.94\end{array}$

$\$ 156.94$

$\begin{array}{llll}1.35396 & 1.07151 & 0.98430 & 0.83532\end{array}$

Ratio: Avg. Fare/SIFL Fare

$\begin{array}{rrrr}1.35396 & 1.07151 & 0.98430 & 0.83532 \\ \$ 27.19 & \$ 7.56 & -\$ 2.36 & -\$ 30.94\end{array}$

Difference: Avg. Fare less SIFL Fare

$\$ 7.56$

$3,240,556 \quad 14,399,799 \quad 11,045,555 \quad 11,731,166$

1,175

$-\$ 476,045$

$-\$ 608,795$

$\$ 2,257,230$

$-\$ 1,567,183$

$\$ 88,106 \quad \$ 108,839 \quad-\$ 26,072 \quad-\$ 362,976$

$\$ 230.60$

0.71305

$-\$ 66.17$

$14,657,434$

$-\$ 969,882$

1,736

2,365

$\$ 205.17$

$\$ 18152$

$\$ 311.63$

0.58248

$\$ 400.45$

0.51235

$-\$ 130.11 \quad-\$ 195.28$

$7,495,655 \quad 8,534,807$

$-\$ 975,284-\$ 1,666,660$

$71,104,972$

$-\$ 3,803,929$

C.2. 2004 GAIN OR LOSS AT 1979 RATIO OF ACTUAL FARE TO SIFL (Second Quarter)

1979 Fare/SIFL Ratio

$\begin{array}{llll}0.97630 & 0.94665 & 0.96563 & 0.92554\end{array}$

0.85024

0.81838

0.72931

2004 Fare at 1979 Fare/S

$\$ 74.99$

$\$ 100.06$

$\$ 145.13$

$\$ 173.89$

$\$ 196.06$

255.03

$\$ 292.05$

Difference from SIFL 2 I

$-\$ 5.64$

$-\$ 5.17 \quad-\$ 13.99$

$-\$ 34.54$

$-\$ 56.60$

$-\$ 108.40$

$-\$ 5,900 \quad-\$ 81,205 \quad-\$ 57,063 \quad-\$ 164,108$

$-\$ 506,204$

$-\$ 424,246$

$\$ 925,146$

$\$ 94,006 \quad \$ 190,045 \quad \$ 30,991 \quad-\$ 198,868 \quad-\$ 463,678$

$-\$ 551,038 \quad-\$ 741,514$

$\$ 2,163,873$

$-\$ 1,640,056$ 
D1. 2003 GAIN OR LOSS AT 2003 RATIO OF ACTUAL FARE TO SIFL (Second Quarter)

\begin{tabular}{|c|c|c|c|c|c|c|c|c|}
\hline Avg. Distance & 216 & 366 & 628 & 884 & 1,177 & 1,738 & 2,358 & \\
\hline Avg. Fare & $\$ 99.91$ & $\$ 110.62$ & $\$ 149.66$ & $\$ 159.70$ & $\$ 170.85$ & $\$ 186.31$ & $\$ 230.88$ & \\
\hline SIFL Fare & $\$ 75.61$ & $\$ 104.05$ & $\$ 147.96$ & $\$ 184.95$ & $\$ 227.29$ & $\$ 307.04$ & $\$ 393.22$ & \\
\hline Ratio: Avg. Fare/SIFL Fare & 1.32132 & 1.06311 & 1.01152 & 0.86349 & 0.75169 & 0.60679 & 0.58715 & 0.75416 \\
\hline Difference: Avg. Fare less SIFL Fare & $\$ 24.30$ & $\$ 6.57$ & $\$ 1.70$ & $-\$ 25.25$ & $-\$ 56.44$ & $-\$ 120.73$ & $-\$ 162.34$ & \\
\hline Passengers & $3,043,795$ & $13,543,502$ & $10,195,272$ & $10,554,226$ & $12,705,209$ & $6,730,654$ & $7,139,448$ & $63,912,106$ \\
\hline Wtd. Premium (\$000) 1/ & $\$ 73,953$ & $\$ 88,932$ & $\$ 17,373$ & $-\$ 266,473$ & $-\$ 717,038$ & $-\$ 812,605$ & $-\$ 1,159,032$ & $-\$ 2,774,890$ \\
\hline \multicolumn{9}{|c|}{ D.2. 2003 GAIN OR LOSS AT 1979 RATIO OF ACTUAL FARE TO SIFL (Second Quarter) } \\
\hline 1979 Fare/SIFL Ratio & 0.97630 & 0.94665 & 0.96563 & 0.92554 & 0.85024 & 0.81838 & 0.72931 & \\
\hline 2003 Fare at 1979 Fare/SIFL Ratio 5/ & $\$ 73.82$ & $\$ 98.50$ & $\$ 142.87$ & $\$ 171.18$ & $\$ 193.25$ & $\$ 251.28$ & $\$ 286.78$ & \\
\hline Difference from SIFL 2/ & $-\$ 1.79$ & $-\$ 5.55$ & $-\$ 5.09$ & $-\$ 13.77$ & $-\$ 34.04$ & $-\$ 55.77$ & $-\$ 106.44$ & \\
\hline Wtd. Premium $\$(000) 3 /$ & $-\$ 5,455$ & $-\$ 75,185$ & $-\$ 51,849$ & $-\$ 145,339$ & $-\$ 432,478$ & $-\$ 375,335$ & $-\$ 759,929$ & $-\$ 1,845,571$ \\
\hline 2003 Pass. Penalty $\$(000) 4 /$ & $\$ 79,409$ & $\$ 164,117$ & $\$ 69,222$ & $-\$ 121,134$ & $-\$ 284,559$ & $-\$ 437,270$ & $-\$ 399,103$ & $-\$ 929,319$ \\
\hline \multicolumn{9}{|c|}{ E.1. 2002 GAIN OR LOSS AT 2002 RATIO OF ACTUAL FARE TO SIFL (Second Quarter) } \\
\hline Avg. Distance & 215 & 367 & 629 & 883 & 1,177 & 1,733 & 2,361 & \\
\hline Avg. Fare & $\$ 99.74$ & $\$ 108.22$ & $\$ 148.09$ & $\$ 158.51$ & $\$ 175.48$ & $\$ 204.00$ & $\$ 250.87$ & \\
\hline SIFL Fare & $\$ 82.74$ & $\$ 114.36$ & $\$ 162.48$ & $\$ 202.76$ & $\$ 249.39$ & $\$ 336.13$ & $\$ 431.84$ & \\
\hline Ratio: Avg. Fare/SIFL Fare & 1.20546 & 0.94634 & 0.91144 & 0.78175 & 0.70363 & 0.60691 & 0.58094 & 0.71449 \\
\hline Difference: Avg. Fare less SIFL Fare & $\$ 17.00$ & $-\$ 6.14$ & $-\$ 14.39$ & $-\$ 44.25$ & $-\$ 73.91$ & $-\$ 132.13$ & $-\$ 180.97$ & \\
\hline Passengers & $3,152,342$ & $13,893,746$ & $10,429,931$ & $10,448,345$ & $11,979,365$ & $6,087,809$ & $6,785,900$ & $62,777,438$ \\
\hline Wtd. Premium (\$000) 1/ & $\$ 53,590$ & $-\$ 85,252$ & $-\$ 150,080$ & $-\$ 462,379$ & $-\$ 885,421$ & $-\$ 804,377$ & $-\$ 1,228,020$ & $-\$ 3,561,940$ \\
\hline \multicolumn{9}{|c|}{ E.2. 2002 GAIN OR LOSS AT 1979 RATIO OF ACTUAL FARE TO SIFL (Second Quarter) } \\
\hline 1979 Fare/SIFL Ratio & 0.97630 & 0.94665 & 0.96563 & 0.92554 & 0.85024 & 0.81838 & 0.72931 & \\
\hline 2002 Fare at 1979 Fare/SIFL Ratio 5/ & $\$ 80.78$ & $\$ 108.25$ & $\$ 156.89$ & $\$ 187.67$ & $\$ 212.04$ & $\$ 275.08$ & $\$ 314.94$ & \\
\hline Difference from SIFL 2/ & $-\$ 1.96$ & $-\$ 6.10$ & $-\$ 5.58$ & $-\$ 15.10$ & $-\$ 37.35$ & $-\$ 61.05$ & $-\$ 116.89$ & \\
\hline Wtd. Premium $\$(000) 3 /$ & $-\$ 6,183$ & $-\$ 84,766$ & $-\$ 58,249$ & $-\$ 157,741$ & $-\$ 447,430$ & $-\$ 371,648$ & $-\$ 793,227$ & $-\$ 1,919,243$ \\
\hline 2002 Pass. Penalty $\$(000) 4 /$ & $\$ 59,772$ & $-\$ 486$ & $-\$ 91,831$ & $-\$ 304,638$ & $-\$ 437,991$ & $-\$ 432,730$ & $-\$ 434,793$ & $-\$ 1,642,697$ \\
\hline
\end{tabular}

F.1. 2001 GAIN OR LOSS AT 2001 RATIO OF ACTUAL FARE TO SIFL (Second Quarter)

\begin{tabular}{|c|c|c|c|c|c|c|c|c|}
\hline Avg. Distance & 210 & 369 & 627 & 888 & 1,186 & 1,727 & 2,357 & \\
\hline Avg. Fare & $\$ 105.06$ & $\$ 113.44$ & $\$ 160.32$ & $\$ 167.46$ & $\$ 184.49$ & $\$ 219.30$ & $\$ 274.10$ & \\
\hline SIFL Fare & $\$ 79.24$ & $\$ 111.37$ & $\$ 157.31$ & $\$ 197.42$ & $\$ 243.19$ & $\$ 325.13$ & $\$ 418.30$ & \\
\hline Ratio: Avg. Fare/SIFL Fare & 1.32585 & 1.01859 & 1.01913 & 0.84824 & 0.75862 & 0.67450 & 0.65527 & 0.79224 \\
\hline Difference: Avg. Fare less SIFL Fare & $\$ 25.82$ & $\$ 2.07$ & $\$ 3.01$ & $-\$ 29.96$ & $-\$ 58.70$ & $-\$ 105.83$ & $-\$ 144.20$ & \\
\hline Passengers & $5,147,597$ & $17,575,285$ & $12,176,619$ & $13,156,962$ & $13,223,665$ & $7,105,462$ & $7,617,883$ & $76,003,473$ \\
\hline Wtd. Premium (\$000) 1/ & $\$ 132,911$ & $\$ 36,381$ & $\$ 36,652$ & $-\$ 394,183$ & $-\$ 776,229$ & $-\$ 751,971$ & $-\$ 1,098,499$ & $-\$ 2,814,938$ \\
\hline \multicolumn{9}{|c|}{ F.2. 2001 GAIN OR LOSS AT 1979 RATIO OF ACTUAL FARE TO SIFL (Second Quarter) } \\
\hline 1979 Fare/SIFL Ratio & 0.97630 & 0.94665 & 0.96563 & 0.92554 & 0.85024 & 0.81838 & 0.72931 & \\
\hline 2001 Fare at 1979 Fare/SIFL Ratio 5/ & $\$ 77.36$ & $\$ 105.43$ & $\$ 151.90$ & $\$ 182.72$ & $\$ 206.77$ & $\$ 266.08$ & $\$ 305.07$ & \\
\hline Difference from SIFL 2/ & $-\$ 1.88$ & $-\$ 5.94$ & $-\$ 5.41$ & $-\$ 14.70$ & $-\$ 36.42$ & $-\$ 59.05$ & $-\$ 113.23$ & \\
\hline Wtd. Premium $\$(000) 3 /$ & $-\$ 9,669$ & $-\$ 104,428$ & $-\$ 65,840$ & $-\$ 193,398$ & $-\$ 481,622$ & $-\$ 419,579$ & $-\$ 862,567$ & $-\$ 2,137,102$ \\
\hline 2002 Pass. Penalty $\$(000) 4 /$ & $\$ 142,580$ & $\$ 140,809$ & $\$ 102,492$ & $-\$ 200,784$ & $-\$ 294,607$ & $-\$ 332,392$ & $-\$ 235,932$ & $-\$ 677,836$ \\
\hline \multicolumn{9}{|c|}{ G.1. 2000 GAIN OR LOSS AT 2000 RATIO OF ACTUAL FARE TO SIFL (Second Quarter) } \\
\hline Avg. Distance & 211 & 371 & 626 & 886 & 1,186 & 1,730 & 2,365 & \\
\hline Avg. Fare & $\$ 107.79$ & $\$ 117.09$ & $\$ 159.87$ & $\$ 176.39$ & $\$ 197.88$ & $\$ 239.16$ & $\$ 310.93$ & \\
\hline SIFL Fare & $\$ 74.47$ & $\$ 104.73$ & $\$ 147.29$ & $\$ 184.78$ & $\$ 228.04$ & $\$ 305.20$ & $\$ 393.21$ & \\
\hline Ratio: Avg. Fare/SIFL Fare & 1.44743 & 1.11806 & 1.08542 & 0.95459 & 0.86774 & 0.78362 & 0.79075 & 0.90459 \\
\hline Difference: Avg. Fare less SIFL Fare & $\$ 33.32$ & $\$ 12.36$ & $\$ 12.58$ & $-\$ 8.39$ & $-\$ 30.16$ & $-\$ 66.04$ & $-\$ 82.28$ & \\
\hline Passengers & $5,484,479$ & $18,059,678$ & $12,966,754$ & $13,037,681$ & $13,032,110$ & $7,036,757$ & $7,657,650$ & $77,275,109$ \\
\hline Wtd. Premium (\$000) 1/ & $\$ 182,742$ & $\$ 223,288$ & $\$ 163,132$ & $-\$ 109,402$ & $-\$ 393,064$ & $-\$ 464,693$ & $-\$ 630,064$ & $-\$ 1,028,061$ \\
\hline \multicolumn{9}{|c|}{ G.2. 2000 GAIN OR LOSS AT 1979 RATIO OF ACTUAL FARE TO SIFL (Second Quarter) } \\
\hline 1979 Fare/SIFL Ratio & 0.97630 & 0.94665 & 0.96563 & 0.92554 & 0.85024 & 0.81838 & 0.72931 & \\
\hline 2000 Fare at 1979 Fare/SIFL Ratio 5/ & $\$ 72.70$ & $\$ 99.14$ & $\$ 142.23$ & $\$ 171.02$ & $\$ 193.89$ & $\$ 249.77$ & $\$ 286.77$ & \\
\hline Difference from SIFL 2/ & $-\$ 1.77$ & $-\$ 5.59$ & $-\$ 5.06$ & $-\$ 13.76$ & $-\$ 34.15$ & $-\$ 55.43$ & $-\$ 106.44$ & \\
\hline Wtd. Premium $\$(000) 3 /$ & $-\$ 9,681$ & $-\$ 100,904$ & $-\$ 65,647$ & $-\$ 179,376$ & $-\$ 445,079$ & $-\$ 390,048$ & $-\$ 815,060$ & $-\$ 2,005,795$ \\
\hline 2000 Pass. Penalty $\$(000) 4 /$ & $\$ 192,424$ & $\$ 324,192$ & $\$ 228,779$ & $\$ 69,974$ & $\$ 52,015$ & $-\$ 74,645$ & $\$ 184,996$ & $\$ 977,734$ \\
\hline
\end{tabular}


H.1. 1999 GAIN OR LOSS AT 1999 RATIO OF ACTUAL FARE TO SIFL (Second Quarter)

\begin{tabular}{|c|c|c|c|c|c|c|c|c|}
\hline Avg. Distance & 211 & 371 & 627 & 883 & 1,182 & 1,733 & 2,367 & \\
\hline Avg. Fare & $\$ 100.22$ & $\$ 110.77$ & $\$ 154.28$ & $\$ 174.50$ & $\$ 193.64$ & $\$ 243.39$ & $\$ 296.08$ & \\
\hline SIFL Fare & $\$ 69.82$ & $\$ 98.19$ & $\$ 138.23$ & $\$ 172.84$ & $\$ 213.27$ & $\$ 286.55$ & $\$ 368.97$ & \\
\hline Ratio: Avg. Fare/SIFL Fare & 1.43540 & 1.12814 & 1.11611 & 1.00959 & 0.90797 & 0.84938 & 0.80245 & 0.94296 \\
\hline Difference: Avg. Fare less SIFL Fare & $\$ 30.40$ & $\$ 12.58$ & $\$ 16.05$ & $\$ 1.66$ & $-\$ 19.63$ & $-\$ 43.16$ & $-\$ 72.89$ & \\
\hline Passengers & $5,370,729$ & $17,048,941$ & $11,781,497$ & $11,422,775$ & $11,867,583$ & $5,996,263$ & $6,666,387$ & $70,154,175$ \\
\hline Wtd. Premium $(\$ 000) 1 /$ & $\$ 163,269$ & $\$ 214,505$ & $\$ 189,088$ & $\$ 18,944$ & $-\$ 232,918$ & $-\$ 258,799$ & $-\$ 485,913$ & $-\$ 391,825$ \\
\hline \multicolumn{9}{|c|}{ H.2. 1999 GAIN OR LOSS AT 1979 RATIO OF ACTUAL FARE TO SIFL (Second Quarter) } \\
\hline 1979 Fare/SIFL Ratio & 0.97630 & 0.94665 & 0.96563 & 0.92554 & 0.85024 & 0.81838 & 0.72931 & \\
\hline 1999 Fare at 1979 Fare/SIFL Ratio 5/ & $\$ 68.17$ & $\$ 92.95$ & $\$ 133.48$ & $\$ 159.97$ & $\$ 181.33$ & $\$ 234.51$ & $\$ 269.09$ & \\
\hline Difference from SIFL 2/ & $-\$ 1.65$ & $-\$ 5.24$ & $-\$ 4.75$ & $-\$ 12.87$ & $-\$ 31.94$ & $-\$ 52.04$ & $-\$ 99.88$ & \\
\hline Wtd. Premium $\$(000) 3 /$ & $-\$ 8,889$ & $-\$ 89,310$ & $-\$ 55,978$ & $-\$ 147,003$ & $-\$ 379,047$ & $-\$ 312,065$ & $-\$ 665,813$ & $-\$ 1,658,105$ \\
\hline 1998 Pass. Penalty $\$(000) 4 /$ & $\$ 172,157$ & $\$ 303,815$ & $\$ 245,066$ & $\$ 165,946$ & $\$ 146,129$ & $\$ 53,266$ & $\$ 179,900$ & $\$ 1,266,280$ \\
\hline
\end{tabular}

I.1. 1998 GAIN OR LOSS AT 1998 RATIO OF ACTUAL FARE TO SIFL (Second Quarter)

\begin{tabular}{|c|c|c|c|c|c|c|c|c|}
\hline Avg. Distance & 211 & 371 & 628 & 884 & 1,184 & 1,734 & 2,370 & \\
\hline Avg. Fare & $\$ 96.47$ & $\$ 104.23$ & $\$ 149.92$ & $\$ 166.85$ & $\$ 188.61$ & $\$ 232.12$ & $\$ 299.73$ & \\
\hline SIFL Fare & $\$ 68.52$ & $\$ 96.36$ & $\$ 135.80$ & $\$ 169.77$ & $\$ 209.58$ & $\$ 281.37$ & $\$ 362.52$ & \\
\hline Ratio: Avg. Fare/SIFL Fare & 1.40783 & 1.08163 & 1.10401 & 0.98282 & 0.89996 & 0.82497 & 0.82679 & 0.93451 \\
\hline Difference: Avg. Fare less SIFL Fare & $\$ 27.95$ & $\$ 7.87$ & $\$ 14.12$ & $-\$ 2.92$ & $-\$ 20.97$ & $-\$ 49.25$ & $-\$ 62.79$ & \\
\hline Passengers & $5,246,150$ & $16,916,900$ & $11,410,035$ & $10,959,494$ & $11,248,510$ & $5,843,292$ & $6,110,832$ & $67,735,213$ \\
\hline Wtd. Premium (\$000) 1/ & $\$ 146,609$ & $\$ 133,068$ & $\$ 161,160$ & $-\$ 31,967$ & $-\$ 235,845$ & $-\$ 287,773$ & $-\$ 383,711$ & $-\$ 498,459$ \\
\hline \multicolumn{9}{|c|}{ I.2. 1998 GAIN OR LOSS AT 1979 RATIO OF ACTUAL FARE TO SIFL (Second Quarter) } \\
\hline 1979 Fare/SIFL Ratio & 0.97630 & 0.94665 & 0.96563 & 0.92554 & 0.85024 & 0.81838 & 0.72931 & \\
\hline 1998 Fare at 1979 Fare/SIFL Ratio 5/ & $\$ 66.90$ & $\$ 91.22$ & $\$ 131.13$ & $\$ 157.13$ & $\$ 178.19$ & $\$ 230.27$ & $\$ 264.39$ & \\
\hline Difference from SIFL 2/ & $-\$ 1.62$ & $-\$ 5.14$ & $-\$ 4.67$ & $-\$ 12.64$ & $-\$ 31.39$ & $-\$ 51.10$ & $-\$ 98.13$ & \\
\hline Wtd. Premium $\$(000) 3 /$ & $-\$ 8,521$ & $-\$ 86,972$ & $-\$ 53,258$ & $-\$ 138,532$ & $-\$ 353,059$ & $-\$ 298,605$ & $-\$ 599,660$ & $-\$ 1,538,607$ \\
\hline 1998 Pass. Penalty $\$(000) 4 /$ & $\$ 155,130$ & $\$ 220,041$ & $\$ 214,418$ & $\$ 106,565$ & $\$ 117,213$ & $\$ 10,832$ & $\$ 215,949$ & $\$ 1,040,148$ \\
\hline \multicolumn{9}{|c|}{ J.1. 1997 GAIN OR LOSS AT 1997 RATIO OF ACTUAL FARE TO SIFL (Second Quarter) } \\
\hline Avg. Distance & 211 & 370 & 626 & 883 & 1,182 & 1,733 & 2,217 & \\
\hline Avg. Fare & $\$ 94.17$ & $\$ 103.13$ & $\$ 143.97$ & $\$ 160.66$ & $\$ 177.31$ & $\$ 226.86$ & $\$ 241.63$ & \\
\hline SIFL Fare & $\$ 68.33$ & $\$ 95.92$ & $\$ 135.14$ & $\$ 169.14$ & $\$ 208.70$ & $\$ 280.41$ & $\$ 341.97$ & \\
\hline Ratio: Avg. Fare/SIFL Fare & 1.37820 & 1.07522 & 1.06534 & 0.94986 & 0.84960 & 0.80904 & 0.70658 & 0.90828 \\
\hline Difference: Avg. Fare less SIFL Fare & $\$ 25.84$ & $\$ 7.22$ & $\$ 8.83$ & $-\$ 8.48$ & $-\$ 31.39$ & $-\$ 53.55$ & $-\$ 100.34$ & \\
\hline Passengers & $5,201,196$ & $16,123,926$ & $10,586,394$ & $10,155,691$ & $10,586,394$ & $5,477,472$ & $2,792,881$ & $60,923,954$ \\
\hline Wtd. Premium (\$000) 1/ & $\$ 134,407$ & $\$ 116,334$ & $\$ 93,480$ & $-\$ 86,129$ & $-\$ 332,292$ & $-\$ 293,305$ & $-\$ 280,244$ & $-\$ 647,751$ \\
\hline \multicolumn{9}{|c|}{ J.2. 1997 GAIN OR LOSS AT 1979 RATIO OF ACTUAL FARE TO SIFL (Second Quarter) } \\
\hline 1979 Fare/SIFL Ratio & 0.97630 & 0.94665 & 0.96563 & 0.92554 & 0.85024 & 0.81838 & 0.72931 & \\
\hline 1997 Fare at 1979 Fare/SIFL Ratio 5/ & $\$ 66.71$ & $\$ 90.80$ & $\$ 130.49$ & $\$ 156.55$ & $\$ 177.44$ & $\$ 229.48$ & $\$ 249.40$ & \\
\hline Difference from SIFL 2/ & $-\$ 1.62$ & $-\$ 5.12$ & $-\$ 4.65$ & $-\$ 12.59$ & $-\$ 31.26$ & $-\$ 50.93$ & $-\$ 92.57$ & \\
\hline Wtd. Premium $\$(000) 3 /$ & $-\$ 8,424$ & $-\$ 82,509$ & $-\$ 49,175$ & $-\$ 127,898$ & $-\$ 330,884$ & $-\$ 278,955$ & $-\$ 258,532$ & $-\$ 1,136,377$ \\
\hline 1997 Pass. Penalty $\$(000) 4 /$ & $\$ 142,831$ & $\$ 198,843$ & $\$ 142,655$ & $\$ 41,769$ & $-\$ 1,408$ & $-\$ 14,351$ & $-\$ 21,712$ & $\$ 488,627$ \\
\hline
\end{tabular}

Annual Data for !979, 1984, 1988

AA.1. 1988 GAIN OR LOSS AT 1988 RATIO OF ACTUAL FARE TO SIFL (Annual data)

\begin{tabular}{|c|c|c|c|c|c|c|c|c|}
\hline Avg. Distance & 199 & 364 & 628 & 882 & 1,183 & 1,732 & 2,364 & \\
\hline Avg. Fare & $\$ 74.02$ & $\$ 91.91$ & $\$ 129.78$ & $\$ 134.22$ & $\$ 143.44$ & $\$ 157.01$ & $\$ 181.15$ & \\
\hline SIFL Fare & $\$ 54.34$ & $\$ 77.82$ & $\$ 111.06$ & $\$ 138.62$ & $\$ 171.28$ & $\$ 229.87$ & $\$ 295.79$ & \\
\hline Ratio: Avg. Fare/SIFL Fare & 1.36216 & 1.18106 & 1.16856 & 0.96826 & 0.83746 & 0.68304 & 0.61243 & 0.85928 \\
\hline Difference: Avg. Fare less SIFL Fare & $\$ 19.68$ & $\$ 14.09$ & $\$ 18.72$ & $-\$ 4.40$ & $-\$ 27.84$ & $-\$ 72.86$ & $-\$ 114.64$ & \\
\hline Passengers & $22,315,520$ & $48,662,250$ & $28,600,620$ & $27,998,300$ & $35,248,960$ & $16,485,950$ & $17,543,350$ & $196,854,950$ \\
\hline Wtd. Premium $(\$ 000) \underline{1} /$ & $\$ 439,169$ & $\$ 685,651$ & $\$ 535,404$ & $-\$ 123,193$ & $-\$ 981,331$ & $-\$ 1,201,166$ & $-\$ 2,011,170$ & $-\$ 2,656,635$ \\
\hline \multicolumn{9}{|c|}{ AA.2. 1988 GAIN OR LOSS AT 1979 RATIO OF ACTUAL FARE TO SIFL (Annual data) } \\
\hline 1979 Fare/SIFL Ratio & 0.97630 & 0.94665 & 0.96563 & 0.92554 & 0.85024 & 0.81838 & 0.72931 & \\
\hline 1988 Fare at 1979 Fare/SIFL Ratio $\underline{5} /$ & $\$ 53.05$ & $\$ 73.67$ & $\$ 107.24$ & $\$ 128.30$ & $\$ 145.63$ & $\$ 188.12$ & $\$ 215.72$ & \\
\hline Difference from SIFL $\underline{2}$ I & $-\$ 1.29$ & $-\$ 4.15$ & $-\$ 3.82$ & $-\$ 10.32$ & $-\$ 25.65$ & $-\$ 41.75$ & $-\$ 80.07$ & \\
\hline Wtd. Premium $\$(000) \underline{3} /$ & $-\$ 28,744$ & $-\$ 202,036$ & $-\$ 109,180$ & $-\$ 288,977$ & $-\$ 904,194$ & $-\$ 688,272$ & $-\$ 1,404,645$ & $-\$ 3,626,048$ \\
\hline 1988 Pass. Penalty $\$(000) \underline{4}$ & $\$ 467,913$ & $\$ 887,687$ & $\$ 644,584$ & $\$ 165,784$ & $-\$ 77,137$ & $-\$ 512,894$ & $-\$ 606,524$ & $\$ 969,413$ \\
\hline
\end{tabular}


AB.1. 1984 GAIN OR LOSS AT 1984 RATIO OF ACTUAL FARE TO SIFL (Annual data)

\begin{tabular}{|c|c|c|c|c|c|c|c|c|}
\hline Avg. Distance & 197 & 360 & 629 & 879 & 1,180 & 1,726 & 2,380 & \\
\hline Avg. Fare & $\$ 53.17$ & $\$ 77.35$ & $\$ 130.74$ & $\$ 137.60$ & $\$ 142.09$ & $\$ 190.03$ & $\$ 235.55$ & \\
\hline SIFL Fare & $\$ 56.18$ & $\$ 80.28$ & $\$ 115.54$ & $\$ 143.74$ & $\$ 177.69$ & $\$ 238.31$ & $\$ 309.27$ & \\
\hline Ratio: Avg. Fare/SIFL Fare & 0.94642 & 0.96350 & 1.13156 & 0.95728 & 0.79965 & 0.79741 & 0.76163 & 0.87403 \\
\hline Difference: Avg. Fare less SIFL Fare & $-\$ 3.01$ & $-\$ 2.93$ & $\$ 15.20$ & $-\$ 6.14$ & $-\$ 35.60$ & $-\$ 48.28$ & $-\$ 73.72$ & \\
\hline Passengers & $22,026,490$ & $41,568,020$ & $19,803,440$ & $18,534,690$ & $24,947,640$ & $9,722,190$ & $10,250,020$ & $146,852,490$ \\
\hline Wtd. Premium $(\$ 000) 1 /$ & $-\$ 66,300$ & $-\$ 121,794$ & $\$ 301,012$ & $-\$ 113,803$ & $-\$ 888,136$ & $-\$ 469,387$ & $-\$ 755,631$ & $-\$ 2,114,040$ \\
\hline \multicolumn{9}{|c|}{ AB.2. 1984 GAIN OR LOSS AT 1979 RATIO OF ACTUAL FARE TO SIFL (Annual data) } \\
\hline 1979 Fare/SIFL Ratio & 0.97630 & 0.94665 & 0.96563 & 0.92554 & 0.85024 & 0.81838 & 0.72931 & \\
\hline 1984 Fare at 1979 Fare/SIFL ratio $\underline{5}$ / & $\$ 54.85$ & $\$ 76.00$ & $\$ 111.57$ & $\$ 133.04$ & $\$ 151.08$ & $\$ 195.03$ & $\$ 225.55$ & \\
\hline Difference from SIFL $\underline{2}$ I & $-\$ 1.33$ & $-\$ 4.28$ & $-\$ 3.97$ & $-\$ 10.70$ & $-\$ 26.61$ & $-\$ 43.28$ & $-\$ 83.72$ & \\
\hline Wtd. Premium $\$(000) \underline{3} /$ & $-\$ 29,332$ & $-\$ 178,038$ & $-\$ 78,647$ & $-\$ 198,367$ & $-\$ 663,898$ & $-\$ 420,795$ & $-\$ 858,091$ & $-\$ 2,427,167$ \\
\hline 1984 Pass. Penalty $\$(000) \underline{4}$ & $-\$ 36,968$ & $\$ 56,243$ & $\$ 379,659$ & $\$ 84,564$ & $-\$ 224,238$ & $-\$ 48,593$ & $\$ 102,459$ & $\$ 313,127$ \\
\hline \multicolumn{9}{|c|}{ AC. 1979 DIFFERENCE FROM SIFL (Annual data) } \\
\hline Avg. Distance & 191 & 364 & 626 & 881 & 1,172 & 1,725 & 2,365 & \\
\hline Avg. Fare & $\$ 39.54$ & $\$ 56.07$ & $\$ 81.47$ & $\$ 97.58$ & $\$ 110.08$ & $\$ 142.75$ & $\$ 164.27$ & \\
\hline SIFL Fare & $\$ 40.50$ & $\$ 59.23$ & $\$ 84.37$ & $\$ 105.43$ & $\$ 129.47$ & $\$ 174.43$ & $\$ 225.24$ & \\
\hline Ratio: Avg.Fare/SIFL Fare & 0.97630 & 0.94665 & 0.96563 & 0.92554 & 0.85024 & 0.81838 & 0.72931 & 0.86051 \\
\hline Difference: Avg. Fare less SIFL Fare & $-\$ 0.96$ & $-\$ 3.16$ & $-\$ 2.90$ & $-\$ 7.85$ & $-\$ 19.39$ & $-\$ 31.68$ & $-\$ 60.97$ & \\
\hline Passengers & $16,622,460$ & $27,598,850$ & $16,976,990$ & $15,023,200$ & $18,769,640$ & $7,668,720$ & $7,822,610$ & $110,482,470$ \\
\hline Passengers/4 (Estimate for 2nd Qtr.) & $4,155,615$ & $6,899,713$ & $4,244,248$ & $3,755,800$ & $4,692,410$ & $1,917,180$ & $1,955,653$ & $27,620,618$ \\
\hline Wtd. Premium (\$000) $\underline{1} /$ & $-\$ 15,958$ & $-\$ 87,212$ & $-\$ 49,233$ & $-\$ 117,932$ & $-\$ 363,943$ & $-\$ 242,945$ & $-\$ 476,945$ & $-\$ 1,354,168$ \\
\hline
\end{tabular}

$\underline{1 /}$ Fare difference, times passengers.

2/ Current SIFL fare, less SIFL fare at 1979 Avg. Fare/ SIFL Fare Ratio.

3/ Fare Difference at 1979 Avg. Fare/SIFL Fare Ratio, times current passengers.

4/ Wtd. Premium in current period, less Wtd. Premium at 1979 Avg. Fare/SIFL Fare Ratio in current period.

5/ SIFL Fare in current period, times 1979 Avg. Fare to SIFL Ratio.

Note: Weighted SIFL fare formula by distance interval by year are:

1979: $\$ 19.81+0.1083(0-500$ miles $)+0.0826(501-1,500$ miles $)+0.0794($ GT 1,500 miles $)$

1984: $\$ 27.04+0.1479(0-500$ miles $)+0.1128(501-1,500$ miles $)+0.1085$ (GT 1,500 miles)

1988: $\$ 26.02+0.1423$ (0-500 miles)+ 0.1085(501-1,500 miles)+ 0.1043(GT 1,500 miles)

Second Quarter (unweighted):

1998: $\$ 31.61+0.1740(0-500$ miles $)+0.1327(501-1,500$ miles $)+0.1276$ (GT 1,500 miles) 1999: $\$ 32.41+0.1773(0-500$ miles $)+0.1352$ (501-1,500 miles) +0.1300 (GT 1,500 miles) 2000: $\$ 34.57+0.1891(0-500$ miles $)+0.1442(501-1,500$ miles $)+0.1386($ GT 1,500 miles $)$ 2001: $\$ 36.88+0.2017(0-500$ miles $)+0.1538(501-1,500$ miles $)+0.1479$ (GT 1,500 miles) 2002: $\$ 38.02+0.2080(0-500$ miles $)+0.1586(501-1,500$ miles $)+0.1524($ GT 1,500 miles $)$ 2003: $\$ 34.66+0.1896(0-500$ miles $)+0.1455(501-1,500$ miles $)+0.1390$ (GT 1,500 miles) 2004: $\$ 35.21+0.1926(0-500$ miles $)+0.1469(501-1,500$ miles $)+0.1412$ (GT 1,500 miles) 2005: $\$ 35.21+0.1926(0-500$ miles $)+0.1469(501-1,500$ miles $)+0.1412$ (GT 1,500 miles) 2006: $\$ 37.85+0.2071$ (0-500 miles) +0.1579 (501-1,500 miles) +0.1518 (GT 1,500 miles) 